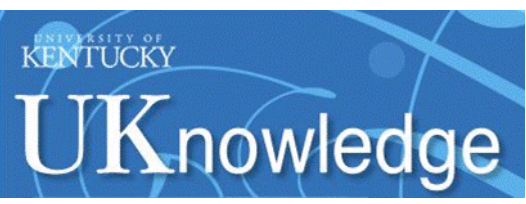

University of Kentucky

UKnowledge

\title{
Interactions between Antiepileptics and Second-Generation Antipsychotics
}

Jose de Leon

University of Kentucky, jdeleon@uky.edu

Vincenza Santoro

University of Messina, Italy

Concetta D'Arrigo

University of Messina, Italy

Edoardo Spina

University of Messina, Italy

Follow this and additional works at: https://uknowledge.uky.edu/psychiatry_facpub

Part of the Psychiatry and Psychology Commons

Right click to open a feedback form in a new tab to let us know how this document benefits you.

\section{Repository Citation}

de Leon, Jose; Santoro, Vincenza; D'Arrigo, Concetta; and Spina, Edoardo, "Interactions between Antiepileptics and Second-Generation Antipsychotics" (2012). Psychiatry Faculty Publications. 39.

https://uknowledge.uky.edu/psychiatry_facpub/39

This Article is brought to you for free and open access by the Psychiatry at UKnowledge. It has been accepted for inclusion in Psychiatry Faculty Publications by an authorized administrator of UKnowledge. For more information, please contact UKnowledge@lsv.uky.edu. 


\section{Interactions between Antiepileptics and Second-Generation Antipsychotics}

\section{Digital Object Identifier (DOI)}

http://dx.doi.org/10.1517/17425255.2012.660918

\section{Notes/Citation Information}

Published in Expert Opinion on Drug Metabolism \& Toxicology, v. 8, Issue 3, p. 311-334.

(c) 2012 Taylor \& Francis Group

This is an Accepted Manuscript of an article published by Taylor \& Francis Group in Expert Opinion on Drug Metabolism \& Toxicology in March 2012, available online: http://www.tandfonline.com/10.1517/ 17425255.2012 .660918 
This is an Accepted Manuscript of an article published by Taylor \& Francis Group in Expert Opinion on Drug Metabolism \& Toxicology on Feb. 15, 2012, available online: http:// www.tandfonline.com/10.1517/17425255.2012.660918

\section{INTERACTIONS BETWEEN ANTIEPILEPTICS AND SECOND-GENERATION ANTIPSYCHOTICS}

Jose de Leon, ${ }^{1}$ Vincenza Santoro, ${ }^{2}$ Concetta D’Arrigo, ${ }^{2}$ Edoardo Spina ${ }^{2}$

${ }^{1}$ University of Kentucky Mental Health Research Center at Eastern State Hospital, Lexington, KY, and Psychiatry and Neurosciences Research Group (CTS-549), Institute of Neurosciences, University of Granada, Granada, Spain.

${ }^{2}$ Section of Pharmacology, Department of Clinical and Experimental Medicine and Pharmacology, University of Messina, Messina, Italy

Corresponding author: Jose de Leon, M.D., UK Mental Health Research Center at Eastern State Hospital, 627 West Fourth St., Lexington, KY 40508. Phone (859) 246-7487. Fax (859) 246-7019.

e-mail: jdeleon@uky.edu 
ABSTRACT:

Introduction: Pharmacokinetic and pharmacodynamic drug interactions (DIs) can occur between antiepileptics (AEDs) and second-generation antipsychotics (SGAPs). Some AED and SGAP pharmacodynamic mechanisms are poorly understood. AED-SGAP combinations are used for treating comorbid illnesses or increasing efficacy, particularly in bipolar disorder.

Areas covered: This article provides a comprehensive review of the interactions between antiepileptics and second-generation antipsychotics. The authors cover pharmacokinetic AED-SGAP DI studies, the newest drug pharmacokinetics in addition to the the limited pharmacodynamic DI studies.

Expert opinion: Dosing correction factors and measuring SGAP levels can help to compensate for the inductive properties of carbamazepine, phenytoin, phenobarbital and primidone. More pharmacokinetic studies are needed to establish the clinical relevance of combining: i) AED strong inducers with amisulpride, asenapine, iloperidone, lurasidone and paliperidone; ii) valproate with aripiprazole, asenapine, clozapine and olanzapine; and iii) high doses of oxcarbazepine ( $\geq 1500 \mathrm{mg} /$ day) or topiramate ( $\geq 400 \mathrm{mg}$ /day) with aripiprazole, lurasidone, quetiapine, risperidone, asenapine and olanzapine. Two pharmacodynamic DIs are beneficial: i) valproate-SGAP combinations may have additive effects in bipolar disorder, and ii) combining topiramate or zonisamide with SGAPs may decrease weight gain. Three pharmacodynamic DIs contributing to decreased safety are common: sedation, weight gain and swallowing disturbances. A few AED-SGAP combinations may increase risk for osteoporosis or nausea. Three potentially lethal but rare pharmacodynamic DIs include pancreatitis, agranulocytosis/leucopenia and heat stroke. Collaboration from all interested parties including: i) drug agencies and pharmaceutical companies; ii) clinicians using these combinations; iii) researchers with expertise in meta-analyses, pharmacoepidemiology, and DI pharmacology; and iv) grant agencies) is needed to progress in this area. 
Keywords: Amisulpride; anticonvulsants; antipsychotics; aripiprazole; asenapine; bipolar disorder; carbamazepine; clozapine; eslicarbazepine; drug interactions; ethosuximide; felbamate; gabapentin; iloperidone; lacosamide; lamotrigine; levetiracetam; lurasidone; olanzapine; oxcarbazepine; paliperidone; pharmacokinetics; phenobarbital; phenytoin; pregabalin; primidone; quetiapine; retigabine; risperidone; rufinamide; stiripentol; tiagabine; topiramate; valproate; vigabatrin; ziprasidone; zonisamide.

\section{Highlights box}

-Drug-drug interactions (DIs) between antiepileptics (AEDs) and second-generation antipsychotics (SGAPs) are frequently clinically relevant.

-More pharmacokinetic DI studies are needed for: i) AED strong inducers with amisulpride, asenapine, iloperidone, lurasidone and paliperidone; ii) valproate with aripiprazole, asenapine, clozapine and olanzapine; and iii) high doses of oxcarbazepine ( $\geq 1500 \mathrm{mg} /$ day) or topiramate ( $\geq 400 \mathrm{mg} /$ day) with SGAPs dependent on CYP3A4 (aripiprazole, lurasidone, quetiapine and risperidone) or UGTs (asenapine and olanzapine) for their metabolism.

-The pharmacodynamic science of AED-SGAP DIs is in its infancy.

-Possible beneficial pharmacodynamic DIs are: i) valproate-SGAP combinations for bipolar disorder, and ii) combining topiramate or zonisamide with SGAPs to decrease weight gain.

-Pharmacodynamic AED-SGAP DIs may increase risk for sedation, weight gain, swallowing disturbances, osteoporosis, nausea, pancreatitis, agranulocytosis/leucopenia and heat stroke. 


\section{Introduction}

Antiepileptics (AED) can be divided into first-generation AEDs (FGAEDs) and second-generation AEDs (SGAEDs). Their clinically relevant drug interactions (DIs) with antipsychotics (APs) are the focus of this review. APs can similarly be divided into first-generation APs (FGAPs) and second-generation antipsychotics APs (SGAPs). Prior DI reviews [1, 2] included a particularly comprehensive review [2], but since its publication [2], no studies of clinically relevant DIs between FGAPs and AEDs have appeared. This article provides an updated review of clinically relevant DIs between AEDs and SGAPs. The introduction provides a brief description of AEDs, SGAPs, their pharmacokinetics, their pharmacodynamics and co-prescription.

\subsection{AEDs}

AED drugs are widely used not only for the treatment of epilepsy, but also for the management of a variety of non-epileptic neurological conditions and psychiatric disorders [3]. The FGAEDs include carbamazepine, ethosuximide, phenytoin, phenobarbital, primidone and valproate (Table 1). The SGAEDs include eslicarbazepine, felbamate, gabapentin, lacosamide, lamotrigine, levetiracetam, oxcarbazepine, pregabalin, retigabine, rufinamide, stiripentol, tiagabine, topiramate, vigabatrin and zonisamide (Table 1). Some SGAEDs (eslicarbazepine, retigabine, stiripentol, and vigabatrin) are not marketed in the US. When compared with FGAEDs, most SGAEDs except for felbamate are characterized by better safety profiles with fewer adverse drug reactions (ADRs) and less DI risk than FGAEDs. The only FGAED that continues to be a first-line choice AED may be valproate, but its teratogenicity risk is contributing to its decreased use in females of fertile age. There are no definitive studies comparing the efficacy of all FGAEDs and the most important SGAEDs in the same study, but in the developed countries SGAEDs, particularly lamotrigine, levetiracetam, and oxcarbazepine, have partially substituted for FGAEDs due to their better safety profiles $[4,5]$.

\subsection{SGAPs}


In recent years, SGAPs (amisulpride, aripiprazole, asenapine, clozapine, iloperidone, lurasidone, olanzapine, paliperidone, quetiapine, risperidone, and ziprasidone) (Table 2) have progressively replaced FGAPs in the developed countries due to better safety profiles for reversible extrapyramidal symptoms and tardive dyskinesia, and better marketing. SGAPs are widely used not only for schizophrenia and bipolar disorder, but for adjuvant treatment of major depressive disorder, psychosis and behavioral disorders in dementia, psychosis associated with Parkinson's disease, resistant obsessive-compulsive disorder, aggressive behavior and irritability in autism spectrum disorders [6].

\subsection{Pharmacokinetics}

There are two basic types of DIs, pharmacokinetic and pharmacodynamic DIs. Pharmacokinetic DIs can be established and quantified by the study of changes in plasma drug concentrations, usually called therapeutic drug monitoring (TDM), and can occur at absorption, distribution, metabolism or excretion of a drug and/or its metabolite(s). The most important pharmacokinetic DIs are the metabolic DIs. This subsection in pharmacokinetics focuses on the metabolism of AEDs and SGAPs and the clinical consequences of pharmacokinetic DIs. Figure 1 discusses the possibility of non-metabolic pharmacokinetic DIs based on the P-glycoprotein (P-gp) or protein binding [7].

\subsubsection{Metabolism}

The cytochrome P450 (CYP) isoenzymes are the most important oxidative enzymes; the uridine diphosphate glucuronosyltransferases (UGTs) are the most important conjugation enzymes. CYP substrates, inhibitors and inducers are well established while those for UGTs are less known.

1.3.1.1. AED metabolism. FGAEDs are extensively metabolized in the liver by CYPs and UGTs (Table 1). By contrast [8], many SGAPs have less propensity for pharmacokinetic DIs because they are not metabolized at all (gabapentin, pregabalin and vigabatrin) and are renally cleared, or undergo minimal hepatic biotransformation (levetiracetam and rufinamide) (Table 1). Four FGAEDs, namely carbamazepine, phenytoin, phenobarbital and primidone, induce the activity of multiple enzymes including CYPs, UGTs and epoxide hydrolase (Table 3) [9]. Once steady state is present, inducers need a 
few weeks, usually 2-4 weeks, to reach maximum effects and to disappear. Thus, sometimes it takes up to one month to see the whole effect of adding or discontinuing an inducer. Among FGAEDs, valproate is a broad-spectrum inhibitor of various drug-metabolizing enzymes including CYP2C9 and UGTs. Some of the newer AEDs may at times act as enzyme inhibitors. Eslicarbazepine, felbamate, oxcarbazepine and topiramate are weak inhibitors of CYP2C19, while stiripentol is a potent inhibitor of CYP1A2, CYP2C19, CYP2D6 and CYP3A4. Eslicarbazepine, felbamate, oxcarbazepine (particularly at dosages $\geq 1500$ $\mathrm{mg} /$ day) [10], rufinamide and topiramate (particularly at dosages $\geq 400 \mathrm{mg}$ day) [11] can induce the activity of CYP3A4 and possibly some UGTs.

1.3.1.2. SGAP metabolism. With the exception of amisulpride and paliperidone, SGAPs are targets of metabolic DIs because they undergo extensive hepatic biotransformation via CYPs and UGTs, which are highly inducible and readily inhibited. SGAPs appear not to be clinically relevant inhibitors or inducers [12] (see competitive inhibition in footnote 2, Table 2).

\subsubsection{Clinical consequence of pharmacokinetic DIs}

Metabolic DIs change the concentration-dose (C/D) ratio that reflects how the drug is cleared from the body at steady state. For SGAPs, the C/D ratio can be represented by a line (linear kinetics). Complicating predictions, some AEDs do not follow linear kinetics (Table 1), thus their C/D ratios may change with different concentrations. Inhibitors increase the $\mathrm{C} / \mathrm{D}$ ratio (lower substrate doses provide the same concentration) while inducers decrease the $\mathrm{C} / \mathrm{D}$ ratio (higher substrate doses are required to reach the same concentration). Pharmacokinetic DI studies can be used to estimate correction factors, which are $>1$ in inducers and $<1$ in inhibitors. A correction factor of 2 indicates that you need to double the dose for the same effect. A correction factor of 0.5 indicates that you need to halve the dose for the same effect. The further the correction factor is from 1, the more relevant the DI may be. The therapeutic window or index also determines the clinical relevance of correction factors. Failing to correct for the therapeutic window after adding or discontinuing inducers or inhibitors may have much greater clinical consequences in drugs with narrow therapeutic windows. 


\subsection{Pharmacodynamics}

Most articles reviewing DIs ignore pharmacodynamic mechanisms of AED and SGAP, which are poorly understood. This subsection provides a very brief reference to the pharmacodynamics of AEDs and SGAPs; they are described more comprehensively in Figures 2 to 5 and their detailed footnotes. At the end of this section, a subsection comments on the types of pharmacodynamic DIs.

\subsubsection{AED pharmacodynamics}

Figure 2 summarizes the AED's mechanism of action in epilepsy, bipolar disorder, anxiety, pain, migraine prophylaxis and weight loss [3, 13-19]. Figure 3 summarizes the AED's mechanism of action associated with major safety issues [20-36].

\subsubsection{SGAP pharmacodynamics}

Figure 4 summarizes the SGAPs' mechanism of action, explaining their efficacy in schizophrenia, other psychoses and other psychiatric disorders [6, 37-42]. Many AP ADRs are explained by their blockade of neurotransmitter receptors (Figure 5) [43-59].

\subsubsection{Pharmacological knowledge and pharmacodynamic DIs}

Pharmacodynamic DIs take place directly at the site of action of a drug or indirectly by interfering with another physiological mechanism. They result in a modification of the pharmacological action of a drug without any change in the plasma concentration and are more difficult to identify and measure than pharmacokinetic DIs. These DIs can be additive (i.e., equal to the sum of the effects of the individual drugs), synergistic (i.e., combined effects are greater than expected from the sum of individual effects) or antagonistic (i.e., combined effects are less than additive) [9]. They can be associated with positive effects (increased efficacy and/or safety) or negative effects (decreased efficacy and/or safety).

\subsection{Co-prescription of AEDs and SGAPs}

AEDs and SGAPs are often prescribed together because co-morbidities may occur: i) AEDs are usually administered for prolonged periods in people with epilepsy and SGAPs may be needed to treat the highly prevalent psychiatric disorders seen in people with epilepsy; ii) autism spectrum disorders are 
associated with very high risk of epilepsy, frequently with poor prognosis, and some SGAPs have been approved in the US market for the treatment of irritability in children with these disorders (Figure 4); or iii) AEDs may be used to treat non-epileptic conditions (e.g., neuropathic pain and migraine) in patients taking SGAPs.

In other cases clinicians co-prescribed them to decrease ADRs (AED medications may be used to treat seizures associated with some SGAPs, clozapine is particularly associated with dosage-related seizures) or increase efficacy: several AEDs (carbamazepine, lamotrigine, and valproate) and SGAPs are approved for bipolar disorder. Therefore, combinations of AEDs and SGAPs are increasingly used in the management of bipolar disorder. Other AEDs are being studied as potential mood stabilizers (oxcarbazepine and zonisamide). Other adjunctive therapies are less established as effective in the literature including: i) valproate or carbamazepine added to SGAPs in people with schizophrenia or schizoaffective disorder to better treat the psychosis or for the management of aggressive behaviors, and ii) lamotrigine added to clozapine for the management of treatment-resistant schizophrenia.

In summary, 1) AEDs and SGAPs are frequently co-prescribed, 2) they have clinically relevant DIs, and 3) there is no recent comprehensive review of this subject.

\section{DI studies and their clinical relevance}

This section provides a comprehensive review of DI studies including three sections that order compounds alphabetically: 1) the metabolic DI studies, starting with a review of the effects of each AED on each SGAP and then the effects of the SGAPs on the AEDs; 2) predictions of the metabolic DIs for new AEDs and SGAPs; and 3) a review of the limited studies on pharmacodynamic DIs. Articles for this review were obtained from a PubMed search with no time limit and through hand-searching of a number of recent journals and recent reviews. Searches were performed for each of the AEDs and SGAPs. This search was beyond the articles previously found and listed in the authors' published literature reviews [9, 12] and DI studies.

\subsection{Pharmacokinetic DI studies}




\subsubsection{Carbamazepine}

Carbamazepine is a powerful inducer of several drug-metabolizing enzymes including CYPs, namely CYP1A2, CYP2A6, CYP2B6, CYP2C9, CYP2C19, CYP3A4, as well as UGTs, such as UGT1A1, UGT2B7, UGT2B15.

2.1.1.1. Carbamazepine on aripiprazole. Carbamazepine decreased the mean area under the curve (AUC) of aripiprazole and dehydro-aripiprazole serum concentrations by $71 \%$ and $69 \%$, respectively, in a study of $30 \mathrm{mg} /$ day of aripiprazole for 14 days and then 4-6 weeks of carbamazepine titrated to concentrations of $8-12 \mu \mathrm{g} / \mathrm{mL}$ [60]. Similarly, a study of 18 schizophrenia patients treated with aripiprazole found 400 $\mathrm{mg}$ /day of carbamazepine, administered for 1 week, caused a significant decrease in aripiprazole and dehydro-aripiprazole concentrations by $64 \%$ and $68 \%$, respectively [61]. A routine TDM study indicated that carbamazepine lowered dose-adjusted concentrations of aripiprazole by $88 \%$ [62].

2.1.1.2. Carbamazepine on clozapine. In a TDM clozapine study, patients on carbamazepine had a mean $50 \%$ lower $\mathrm{C} / \mathrm{D}$ ratio of clozapine than the monotherapy group [63]. In a comparison of the effects of carbamazepine and oxcarbazepine on clozapine serum concentrations in 12 patients, Tiihonen et al. found that the clozapine concentration was $47 \%$ lower with carbamazepine than with oxcarbazepine [64]. Carbamazepine's inducing effect on CYP1A2- and CYP3A4-mediated clozapine metabolism probably explains these results.

2.1.1.3. Carbamazepine on olanzapine. A DI study of 11 healthy volunteers assessed a single $10 \mathrm{mg}$ olanzapine dose before and after administration of carbamazepine $400 \mathrm{mg} / \mathrm{day}$ for 18 days [65]. Carbamazepine resulted in a $46 \%$ increase in olanzapine clearance and in a $34 \%$ decrease in its AUC. In carbamazepine patients the median dose-normalized olanzapine concentrations were $36-71 \%$ lower than in those in monotherapy according to TDM studies [66-69]. Specifically, Linnet and Olesen evaluated the influence of carbamazepine on olanzapine glucuronidation in a TDM study [67]. Two median differences were significant between 16 carbamazepine patients and 31 in monotherapy: i) free olanzapine C/D ratio was $38 \%$ lower $(3.6 \mathrm{nmol} / \mathrm{l} / \mathrm{mg}$ versus $5.8 \mathrm{nmol} / \mathrm{l} / \mathrm{mg})$, and ii) glucuronidated fraction (79\% versus $43 \%)$ 
[67]. Carbamazepine lowered free olanzapine concentration by increasing glucuronidation metabolism. All of these studies clearly indicated that carbamazepine increases olanzapine metabolism by CYP1A2and UGT-induction.

2.1.1.4. Carbamazepine on paliperidone. CYP inhibitors or inducers were not expected to have a significant influence on paliperidone metabolism but the US package insert describes $400 \mathrm{mg} / \mathrm{day}$ of carbamazepine as decreasing the mean steady-state serum peak concentration $\left(\mathrm{C}_{\max }\right)$ and the AUC of paliperidone by approximately $37 \%$, due to a $35 \%$ increase in the renal clearance of paliperidone. This is attributed to carbamazepine induction of the renal P-gp.

2.1.1.5. Carbamazepine on quetiapine. Carbamazepine $\left(600 \mathrm{mg} /\right.$ day) decreased quetiapine $\mathrm{C}_{\max }$ by $80 \%$ and AUC by $87 \%$ and increased oral clearance by a 7.5 -fold increase in a pharmacokinetic study of 18 psychiatric patients [70]. TDM studies [71-74] provided similar results. In particular, in a large routine TDM database, the mean quetiapine $\mathrm{C} / \mathrm{D}$ ratio was 9 times lower $(0.02$ versus 0.18$)$ and significantly lower $(95 \%$ confidence intervals $0.02-0.03$ versus $0.17-0.19, \mathrm{p}<0.001)$ for the 39 carbamazepine-treated patients versus the 1123 patients on quetiapine monotherapy [72]. The DI clinical implications were demonstrated in three patients taking carbamazepine 400-800 $\mathrm{mg}$ /day in which serum quetiapine concentrations could not be detected $(<25 \mathrm{ng} / \mathrm{mL})$ despite taking $700 \mathrm{mg} /$ day [75]. These massive pharmacokinetic changes are explained by the potent inducing effect of carbamazepine on CYP3A4mediated quetiapine metabolism.

2.1.1.6. Carbamazepine on risperidone. A case report first reported that serum risperidone active moiety (risperidone and its pharmacologically active metabolite 9-hydroxy-risperidone) doubled after carbamazepine discontinuation, leading to an ADR [76]. A subsequent study indicated that risperidone moiety was approximately 1.4 times lower in 11 carbamazepine patients versus 23 patients on risperidone alone [77]. In 5 patients assessed on and off carbamazepine co-medication, risperidone moiety was 1.5 times lower on carbamazepine [77]; in 11 other patients it was 1.8 times lower [78]. The clinical 
relevance of the increase in risperidone metabolism attributed to the carbamazepine CYP3A4-inducing effects was demonstrated by an acute psychotic exacerbation in a case report [79].

2.1.1.7. Carbamazepine on ziprasidone. Carbamazepine ( $400 \mathrm{mg} /$ day) lowered ziprasidone mean $\mathrm{C}_{\max }$ by $27 \%$ and mean $\mathrm{AUC}_{0-12 \mathrm{~h}}$ by $36 \%$ in 19 healthy volunteers taking $40 \mathrm{mg}$ /day of ziprasidone [80]. Carbamazepine probably induced CYP3A4-mediated ziprasidone metabolism.

2.1.1.8. SGAPs on carbamazepine. Two weeks after the addition of risperidone $(1 \mathrm{mg} / \mathrm{day})$ the mean steady-state carbamazepine concentrations mildly increased by $19 \%$ in 8 epileptic patients [81], probably due to competitive inhibition of CYP3A4. Adding quetiapine led to a pharmacokinetic DI and ADRs in 2 patients [82], probably due to the competitive inhibition of CYP3A4.

\subsubsection{Lamotrigine}

Lamotrigine does not appear to be a CYP inhibitor or inducer but is a weak UGT inducer [9].

2.1.2.1. Lamotrigine on clozapine. A case report associated a clozapine ADR with a 3-fold increase in serum clozapine concentrations when lamotrigine was added [83]. However two studies (a randomized clinical trial [RCT] in 34 hospitalized treatment-resistant patients [84] and a pharmacokinetic study in 11 patients stabilized on clozapine [85]) found no serum clozapine concentration changes during lamotrigine treatment up to $200 \mathrm{mg} /$ day.

2.1.2.2. Lamotrigine on olanzapine. Although UGT1A4 metabolizes both lamotrigine and olanzapine, two studies of healthy volunteers using low lamotrigine doses (50 and $200 \mathrm{mg} /$ day) found no effects on olanzapine pharmacokinetics $[86,87]$. A mild (15\%) but significant increase in steady-state olanzapine serum concentration was found in 14 patients taking olanzapine (10-20 mg/day) after adding $100 \mathrm{mg} / \mathrm{day}$ of lamotrigine [85]. By using a mixed model, Botts et al. confirmed that lamotrigine behaved as an olanzapine inhibitor in smokers, increasing the $\mathrm{C} / \mathrm{D}$ ratio by $35 \%$, whereas the lamotrigine produced a mild non-significant decrease in olanzapine C/D ratio in nonsmokers [69]. 
2.1.2.3. Lamotrigine on quetiapine. A large TDM study reported a slight (17\%) and significant $17 \%$ decrease in quetiapine C/D ratio in 147 lamotrigine patients when 1123 were on quetiapine monotherapy [62].

2.1.2.4. Lamotrigine and risperidone. An ADR case report described a 5-6-fold elevation in risperidone levels after adding lamotrigine [88]. However, a study of 10 psychotic patients stabilized on risperidone (3-6 mg/day), demonstrated that up to $200 \mathrm{mg}$ /day of lamotrigine had no influence on serum risperidone moiety [85].

2.1.2.5. SGAPs on lamotrigine. There was no influence on lamotrigine levels in: i) a TDM study (N=829) with clozapine, risperidone or olanzapine co-prescription [89], and ii) an aripiprazole study with 30 $\mathrm{mg} /$ day in 18 bipolar patients [90].

\subsubsection{Phenobarbital/phenytoin}

Phenobarbital and phenytoin are considered powerful and promiscuous inducers of CYPs, (including CYP1A2, CYP2C, and CYP3A4) as well as UGTs.

2.1.3.1. Phenobarbital/phenytoin on clozapine. Two patients had a psychotic exacerbation after adding phenytoin, which decreased clozapine levels by $65-85 \%$ [91]. Lane et al. described a patient with a remarkable elevation of clozapine levels 2 weeks after phenobarbital discontinuation [92]. Facciolà et al. found that serum clozapine concentrations were significantly lower in 7 phenobarbital-treated patients than in 15 monotherapy patients $(232 \pm 104 \mathrm{ng} / \mathrm{ml}$ versus $356 \pm 13 \mathrm{ng} / \mathrm{ml})$ and attributed this decrease to CYP1A2- and CYP3A4-induction [93].

2.1.3.1. Phenytoin on quetiapine. Quetiapine clearance increased more than 5 -fold from $80.3 \pm 35.91 / \mathrm{hr}$ to $440 \pm 214 \mathrm{l} / \mathrm{hr}$ when comparing 10 patients on $750 \mathrm{mg}$ /day after receiving phenytoin (300 $\mathrm{mg} /$ day) [94].

\subsubsection{Oxcarbazepine}

Oxcarbazepine is a keto-analog of carbamazepine. Unlike carbamazepine, this AED seems to be a modest CYP3A4 inducer [9]. As previously mentioned, carbamazepine was associated with lower clozapine levels in 12 patients when compared with oxcarbazepine [64]. Minimal and not significant 
serum concentration modifications occurred after a 5-week treatment of oxcarbazepine (900-1200 $\mathrm{mg} /$ day $)$ in psychotic patients stabilized on risperidone $(2-6 \mathrm{mg} / \mathrm{day} ; \mathrm{n}=12)$ or olanzapine $(5-20 \mathrm{mg} / \mathrm{day}$; $\mathrm{n}=13)[95]$.

\subsubsection{Topiramate}

Topiramate is a weak inhibitor of CYP2C19 and a weak inducer of CYP3A4 [9]. Adding up to $200 \mathrm{mg} /$ day of topiramate brought no serum concentration modifications for clozapine (250-500 mg/day, $\mathrm{n}=10)$, olanzapine $(10-20 \mathrm{mg} /$ day, $\mathrm{n}=12)$, risperidone $(3-6 \mathrm{mg} /$ day, $\mathrm{n}=9)$ or quetiapine $(200-600 \mathrm{mg} / \mathrm{day}$, $\mathrm{n}=7$ ) [96]. It cannot be ruled out that higher topiramate doses may have an inductive effect in these SGAPs.

\subsubsection{Valproate}

Valproate has traditionally been considered a broad-spectrum metabolic enzyme inhibitor. It inhibits CYP2C9 competitively, CYP2C19 and CYP3A4 weakly and has no effects on CYP1A2, CYP2D6, and CYP2E1. It inhibits UGT enzymes (UGT1A4 and UGT2B7) [9]. A recent human hepatocyte study surprisingly demonstrated that valproate may induce some enzymes (CYP3A4 and P-gp gene expression) [97].

2.1.6.1. Valproate on aripiprazole. A decrease of $26 \%$ in the aripiprazole $\mathrm{C}_{\max }$ and of $24 \%$ in the aripiprazole AUC with minimal effects on the active metabolite of aripiprazole after valproate addition was found in an open study of 10 schizophrenia patients [98]. Similarly, in a TDM study aripiprazole C/D was $24 \%$ lower in 7 patients co-medicated with valproate than in 23 on aripiprazole monotherapy [62]. Aripiprazole is a CYP3A4 and P-gp substrate; thus valproate may mildly induce CYP3A4 and/or P-gp. Both can decrease intestine drug absorption.

2.1.6.2.Valproate on clozapine. Early studies provided conflicting findings of increases and decreases of clozapine metabolism by valproate, which were unlikely to be clinically significant [reviewed by 99 ].

The three best studies [100-102] suggested that valproate might inhibit clozapine conversion to norclozapine via CYP1A2 or CYP3A4. In contrast, Finley and Warner found in four male patients that 
clozapine concentrations decreased by $41 \%$ when valproate was administered [103]. By using a statistical mixed model that estimated the effect sizes of co-medications on clozapine levels after correcting for confounding variables, Diaz et al. found that valproate appeared to act as a clozapine inhibitor in non-smokers and as an inducer in smokers [99]. These findings may account for the inconsistent valproate results on clozapine metabolism.

2.1.6.3. Valproate on olanzapine. As valproate and olanzapine share common metabolic pathways, a metabolic DI can occur. TDM studies found no valproate influence on olanzapine metabolism [69, 104]. However, in four patients stabilized on olanzapine, valproate (1000-2700 mg/day) decreased olanzapine levels by $50 \%$ with a psychiatric deterioration in three of them [105]. Valproate co-administration (600$2000 \mathrm{mg} /$ day) was associated with a significant decrease in mean serum olanzapine concentrations from $32.9 \pm 9.7 \mathrm{ng} / \mathrm{mL}$ at baseline to $27.4 \pm 9.8 \mathrm{ng} / \mathrm{mL}$ at week 2 , and to $26.9 \pm 9.2 \mathrm{ng} / \mathrm{mL}$ at week 4 in 18 psychotic patients who had no relapses [106]. Serum olanzapine concentration drop varied from 2 to 4 weeks and with valproate concentration and is likely to be explained by valproate induction on olanzapine metabolism by CYPs or UGT. These changes, although statistically significant, were small and presumably not clinically significant. However, as the valproate and olanzapine combination is increasingly used, further studies are necessary to elucidate the mechanisms (induction, competitive inhibition and/or protein binding displacement), severity and duration of this DI and to understand whether there are any circumstances (e.g., high or low olanzapine or valproate doses) in which this DI may acquire clinical relevance [107].

2.1.6.4. Valproate on quetiapine. Valproate studies on quetiapine metabolism provided inconsistent results. A $77 \%$ increase in quetiapine $\mathrm{C} / \mathrm{D}$, when compared to quetiapine monotherapy in 9 patients taking valproate, led Aichorn et al. to propose a CYP3A4-inhibition of quetiapine metabolism by valproate [108]. However no relevant changes in quetiapine metabolism were found in two TDM routine studies $[72,73]$ and in a formal pharmacokinetic study in 34 psychotic patients taking $300 \mathrm{mg} /$ day of quetiapine and $1000 \mathrm{mg} /$ day of divalproex [109]. 
2.1.6.5. Valproate on risperidone. No major changes in risperidone moiety were found in: i) a pharmacokinetic study comparing 23 patients on monotherapy versus 10 on valproate (1200-1500 $\mathrm{mg} /$ day) [77], ii) its extension to 3 patients on/off valproate [77], and iii) another pharmacokinetic study of 22 bipolar patients taking valproate $(1000 \mathrm{mg} / \mathrm{day})$ in which half were randomized to placebo or risperidone up to $4 \mathrm{mg} /$ day [110]. This is consistent with the absence of an inhibitory effect of valproate on CYP2D6 or CYP3A4, the major risperidone metabolic pathways.

\subsection{Predicting metabolic DIs for new compounds}

\subsubsection{Other AEDs}

The DI information for other SGAEDs is limited. Eslicarbazepine and rufinamide (as well as the older felbamate) are mild CYP3A4-inducers. Rufinamide is also a possible UGT-inducer. Eslicarbazepine, felbamate and rufinamide have limited potential to induce SGAP metabolism. As CYP2C19 is not important in SGAP metabolism, the weak CYP2C19 inhibition by eslicarbazepine and felbamate is not likely to be relevant. Stiripentol is a potent inhibitor of CYP2C19, CYP1A2, CYP2D6, and CYP3A4 but is only used in Europe for the treatment of severe myoclonic epilepsy in infancy and is not likely to be co-prescribed with SGAPs.

\subsubsection{New SGAPS}

2.2.2.1. Asenapine. UGT1A4 and CYP1A2 metabolize asenapine. Valproate (1000 mg/day for 9 days) substantially reduced the formation of the N-glucuronide (AUC reduced 7.4-fold) and moderately reduced that of N-desmethyl-asenapine (AUC reduced 30\%) but did not affect asenapine AUC in an open-label, randomized, 2-way crossover study in 24 healthy male volunteers receiving $5 \mathrm{mg}$ of asenapine alone or a low valproate dose. The study's authors, who were from the asenapine-marketing company, concluded that low-dose valproate, although almost completely inhibiting asenapine glucuronidation, did not affect asenapine clearance [111]. Asenapine's package insert indicates that: 1) $800 \mathrm{mg} /$ day of carbamazepine for 15 days had small effects on asenapine AUC (16\% decrease), and 2) no dosage adjustments are required. 
Independent studies using multiple dosing are required to verify that the valproate and carbamazepine DIs with asenapine have no clinical relevance.

2.2.2.2. Iloperidone. Iloperidone is metabolized by CYP2D6 and CYP3A4 [112]. CYP3A4 inhibitors have clinically relevant effects on iloperidone levels. There are no published studies of potent CYP3A4 inducers which are expected to relevantly increase iloperidone metabolism.

2.2.2.3. Lurasidone. Lurasidone is metabolized by CYP3A4 [113]. According to the US package insert, rifampin, a potent CYP3A4-inducer, decreased lurasidone AUC 5-fold. There are no published studies of potent CYP3A4 inducers which are expected to dramatically increase lurasidone metabolism. It is possible that in high doses oxcarbazepine or topiramate may influence lurasidone levels.

\subsection{Limited studies on pharmacodynamic DIs}

This subsection classifies pharmacodynamic DIs as those increasing efficacy, increasing safety, decreasing efficacy, and decreasing safety. The most important are included in Table 5.

\subsubsection{Pharmacodynamic DIs increasing efficacy}

Several SGAPs have been approved in the US for mania as adjuvant therapy to valproate (and lithium), including aripiprazole, asenapine, quetiapine, risperidone and olanzapine. In the RCTs, tested SGAPs were significantly more efficacious than adding placebo to valproate (or lithium). Thus, an additive (or synergistic) effect (see subsection 1.4.3.) between valproate and SGAPs is expected in mania

(Table 5). In a review, Ketter described the response rate to valproate (and lithium) as increasing from $21 \%$ to $42 \%$ when adding SGAPs [114], which suggests additive rather than synergistic effects.

\subsubsection{Pharmacodynamic DIs increasing safety}

Topiramate and zonisamide can decrease weight (Figure 2 and Table 5). Topiramate has been associated with reversing SGAP-induced weight gain in an open study [115].

\subsubsection{Pharmacodynamic DIs decreasing efficacy}

Figures 2-5 indicate that AEDs and SGAPs sometimes have opposite actions. All SGAPs, but particularly clozapine and to a lesser extent olanzapine and quetiapine (Figure 5), have potential to 
decrease the seizure threshold and therefore contribute to seizures [53]. If a patient with epilepsy needs an SGAP, the potential for increased seizures needs to be considered. This is easily managed by monitoring AED treatment closely and considering increased AED doses, but in patients with not-well-controlled seizures, adding an SGAP that lowers the seizure threshold may produce a clinically relevant pharmacodynamic DI.

In epileptic patients, some AEDs (ethosuximide, levetiracetam, tiagabine, topiramate, vigabatrin and zonisamide) have rarely been associated with psychosis (usually a transient paranoid psychosis; Figure 3). As the pharmacodynamic mechanism is unknown, clinicians may want to remember this risk when considering co-prescribing them with SGAPs in patients whose psychosis is not well-controlled. In epileptic patients, some AEDs (particularly barbiturates, topiramate and vigabatrin, and less frequently felbamate, levetiracetam, tiagabine, and zonisamide) have been associated with depression (Figure 3). Clinicians may want to remember this risk when considering co-prescribing these AEDs with SGAPs in patients with bipolar disorder or treatment-resistant depression since they have the potential to antagonize the antidepressant SGAP properties. A Food and Drug Administration (FDA) meta-analysis of the placebo RCTs suggests that patients taking AEDs have an increased risk of suicidal thoughts and behaviors observed 1 week after taking the medication; the risk continues for at least 24 weeks which has led to a warning in the package inserts of all anticonvulsants [116]. Recently, reviews questioned the FDA warning in the prescription packages for all AEDs [117] and large pharmacoepidemiological studies suggested contradictory findings for AEDs in general $[118,119]$. In our opinion, 1) the FDA decision to include a warning about increased suicide risk in all antiepileptic prescribing information has increased awareness, but oversimplified a complex matter; 2) the risk of completed suicide in persons with suicidal ideation is probably low, while completed suicide risk increases 40-fold after a prior attempt [120]; and 3) other factors such as medical and psychiatric illnesses can partially explain the increased suicide risk in patients taking AEDs.

\subsubsection{Pharmacodynamic DIs decreasing safety.}


There are multiple pharmacodynamic DIs that have potential to increase ADRs by additive or synergistic effects. These DIs are likely to be clinically relevant but have not been systematically studied. They can be divided into common, probably less common and rare, but potentially lethal, categories.

Three common pharmacodynamic DIs are sedation, weight gain and swallowing disturbances (Table 5). A recent well-controlled 12-month study indicated that the valproate-olanzapine combination was worse for metabolic syndrome than the valproate-risperidone combination [121]. Dysphagia is particularly frequent in patients with intellectual disabilities or dementia. Although it has not been studied additive or synergistic pharmacodynamic DI actions on swallowing disturbances are likely between AEDs and SGAPs. Table 5 emphasizes two probably uncommon pharmacodynamic DIs, nausea/vomiting and osteoporosis, which have never been studied, and includes three rare, but potentially lethal pharmacodynamic DIs: pancreatitis, agranulocytosis and heat stroke. Carbamazepine and clozapine should not be combined due to their risk for agranulocytosis. Valproate and other SGAPs besides clozapine have occasionally been associated with neutropenias due to not well-understood mechanisms. Rahman et al. have described neutropenia and leucopenia cases with the combination of valproate and quetiapine [122].

\section{Conclusion}

This section and Table 5 provide a summary of the most important practical DI information for clinicians.

\subsection{Pharmacokinetic DIs and clinical implications}

Carbamazepine, phenobarbital, phenytoin and primidone are potent inducers that are likely to have clinically relevant effects on several SGAP levels (Table 5). Adding any of these inducers (in the absence of other inducers) may be associated with a decrease in SGAP serum concentration that may be associated with lack of efficacy. The discontinuation of these inducers (when other inducers are not prescribed) may be associated with an increase in SGAP serum concentration that may be associated with ADRs. The best 
way to control for these DIs is by checking SGAP TDM. As SGAP TDM may not be available, Table 5 provides a best estimation of a correction factor (Figure 1) based on the limited available literature.

The pharmacokinetic DIs associated with valproate or the mild AED inducers eslicarbazepine, felbamate, oxcarbazepine, rufinamide and topiramate (Table 5) are not likely to be clinically relevant in most patients taking SGAPs, but it cannot be ruled out that in some unusual patients they may have clinical relevance. In that sense, clinicians may need to be watchful when using high doses of oxcarbazepine ( $\geq 1500 \mathrm{mg} /$ day) [10] or topiramate ( $\geq 400 \mathrm{mg} /$ day) [11], particularly with highly inducible SGAPs such as quetiapine or lurasidone.

\subsection{Pharmacodynamic DIs and clinical implications}

As described in Section 2.3, the literature is very limited in the description of pharmacodynamic DIs but in our experience these types of DIs are very relevant in clinical practice (Table 5). Two pharmacodynamic DIs can be considered positive: i) the additive effects for mania and bipolar maintenance when combining valproate and SGAPs and ii) the decrease in weight that may be associated with combining topiramate or zonisamide with SGAPs.

In our experience with neurologists managing AED prescriptions and psychiatrists prescribing SGAPs, these specialists rarely pay enough attention to the other's prescriptions, which may lead to high potential for pharmacodynamic DIs. Three additive DIs are common: increased sedation, weight gain and swallowing disturbances. However, different AEDs and SGAPs have different risks for sedation or weight gain (Table 5). As swallowing impairment is usually a neglected ADR in published studies, there is no information on whether different AEDs or SGAPs have different risks for swallowing impairment. From the probably uncommon pharmacodynamic DIs, Table 5 highlights the potential for increased risk for osteoporosis and nausea for a few combinations of AEDs and SGAPs. Finally, Table 5 describes three potentially lethal pharmacodynamic DIs: pancreatitis, agranulocytosis/leucopenia and heat stroke. These ADRs are very rare and we are not sure that combinations of AEDs and SGAPs increase their risk but 
pharmacological mechanisms suggest that it is a possibility and clinicians need to remember that in order to prevent or quickly diagnose these ADRs.

\section{Expert opinion}

We have excellent understanding of the clinical relevance of DIs associated with the inductive properties of carbamazepine, phenytoin, phenobarbital and primidone and with the inhibitory properties of valproate. Unfortunately, the DI studies with SGAPs are rather limited but adding or discontinuing phenytoin, phenobarbital and primidone are likely to have clinically relevant effects on SGAP treatments. Table 5 provides correction factors based on the limited available literature. These correction factors were calculated using the available pharmacokinetic studies which summarize the data, assuming that the average patient represents the population well; however, there is extensive pharmacokinetic variability between patients, and TDM measurements should be advised for optimal titration of the dosage in each individual. In spite of their limitations, these corrections factors are useful because: 1) many clinicians have no access to antipsychotic TDM and, as a matter of fact, there is limited clinical data on some SGAP TDM (amisulpride, aripiprazole, paliperidone, quetiapine, and ziprasidone) and very limited data on three compounds (asenapine, iloperidone and lurasidone); and 2) in our experience, having the correction factor helps clinicians to make decisions. With a correction factor of 5, quetiapine and lurasidone are poor SGAP choices for patients taking powerful AED inducers. The correction factors may not fully account for all of the possible risks of treatment because of the limited studies available; thus, there will be a need to periodically update these correction factors as new knowledge becomes available.

Eslicarbazepine, felbamate, and rufinamide are thought to be mild inducers but there are no studies on SGAPs to verify their limited clinical relevance. A serious limitation of the SGAP DI literature is the lack of studies in clinical samples with high doses of oxcarbazepine ( $\geq 1500 \mathrm{mg} /$ day $)$ or topiramate $(\geq 400$ $\mathrm{mg}$ /day) that would establish whether or not they induce in a clinically relevant way SGAPs dependent on CYP3A4 (aripiprazole, lurasidone, quetiapine and risperidone) or UGTs (asenapine and olanzapine) for their metabolism. As Table 5 indicates, it is very likely that AED inducers have major effects in 
lurasidone metabolism since rifampin, another potent and widespread inducer, increased lurasidone metabolism by a factor of 5. Clinicians may need to be very careful with iloperidone and particularly asenapine. Asenapine metabolism by UGT1A4 and CYP1A2 suggests asenapine has major potential for being induced by carbamazepine, phenytoin, phenobarbital and primidone. There is no way of providing a correction factor since we are unaware of any other drug with similar metabolism to asenapine. On the other hand, one would like to see asenapine DI studies with repeated dosing in clinical samples, to be reassured that valproate effects on asenapine metabolism can be ignored by clinicians. We suspect that the valproate effects are small in most patients taking SGAPs but we keep surprising ourselves by finding unexpected valproate DIs, particularly as a possible inducer of: i) clozapine in smokers [99], or ii) olanzapine [106], which may be relevant in extreme conditions (valproate levels $\geq 80 \mu \mathrm{g} / \mathrm{ml}$ and olanzapine doses $\leq 10 \mathrm{mg} / \mathrm{d}$ ) [107]. Paliperidone studies with strong inducers published by independent investigators are needed.

It is not easy to conduct DI studies using clinically relevant doses. Pharmaceutical companies tend to invest in simple pharmacokinetic DI studies in volunteers frequently using single dosing to get approval for the marketing of their drugs, but this type of pharmacokinetic study rarely reflects clinical practice. DI information on package inserts is usually not designed to provide easy information to help clinicians to correct pharmacokinetic DIs with dose changes. The pharmacokinetic science on AEDSGAP combinations may be in its adolescence and needing maturation, while pharmacodynamic DI science appears to be in its infancy. None of the studies combining AEDs with mood stabilizers and SGAPs explore whether the combinations are additive or synergistic. Recent meta-analyses determined the effects of different monotherapies in mania, bipolar depression or maintenance but there is no published meta-analysis of the combinations, although most patients are treated with combinations. There are almost no well-controlled studies of AEDs or SGAPs in patients with aggressive behaviors or in adults with epilepsy and intellectual disabilities, although clinicians use AED-SGAP combinations frequently in them. 
It would be naïve to simply conclude that more studies of AED-SGAP DIs are needed. They are obviously needed, but the lack of funding for clinical research is a major limitation. To progress in this area, collaboration from all interested parties is needed, including: i) drug agencies and pharmaceutical companies; ii) clinicians using AED-SGAP combinations; iii) researchers with expertise in a) metaanalyses, b) pharmacoepidemiology, and c) DI pharmacology; and iv) grant agencies.

Drug agencies should be more insistent upon rapid approval of new SGAPs in bipolar disorder and require: i) thorough studies of the pharmacodynamic and pharmacokinetic DIs with carbamazepine, lamotrigine, lithium and valproate; and ii) clear package insert guidelines of how to better avoid or correct for pharmacodynamic and pharmacokinetic DIs. Carbamazepine is an anti-manic agent and probably a mood stabilizer, but it took too many years to get FDA approval for a bipolar disorder indication due to lack of interest from the pharmaceutical companies. Carbamazepine use is limited by its potential for toxicity, teratogenicity and DIs. If oxcarbazepine is judged to be as effective as carbamazepine in bipolar disorder, carbamazepine should replace oxcarbazepine. The FDA may need to think "out of the box" and look for new ways to encourage pharmaceutical companies possibly interested in marketing oxcarbazepine in bipolar disorder by providing special "deals", assuming the companies seriously want to study DI issues, including the possible impact of high oxcarbazepine doses. Similarly, as several AEDs with chemical formulations similar to already marketed AEDs are being studied for approval for epilepsy (e.g., DP-valproic acid or phosphatidylcholine estric conjugate of valproic acid) the FDA and other agencies need to think "out of the box" about encouraging and simplifying the process of approval of these new AEDs for bipolar disorder.

Clinicians frequently co-prescribe AEDs and SGAPs. Neurologists may prescribe SGAPs in their patients with epilepsy or other non-epileptic conditions (pain or migraine) that need treatment for psychosis, bipolar disorder or other SGAP off-label conditions. Psychiatrists may prescribe AEDs as mood stabilizers or for off-label indications in patients taking SAGPs. Thousands of US patients take these combinations. There is great need of naturalistic studies describing possible additive or synergistic 
efficacy and, more importantly, the long-term safety of these combinations. Are early sedation or early nausea and vomiting more frequent in some of these combinations that in the various monotherapies? Is swallowing impairment or osteoporosis a long-term issue in vulnerable patients taking some of these combinations for years?

Researchers with expertise in meta-analysis may need to develop better methods to study: i) safety of AED-SGAP combinations by comparing ADRs in available SGAP RCTs in monotherapy in schizophrenia versus those on adjuvant therapy in bipolar disorder, and ii) how bipolar disorder studies can better compare efficacy of individual drugs versus drug combinations. Researchers with expertise in pharmacoepidemiology need to explore whether rare ADRs such as risk of pancreatitis, agranulocytosis/leucopenia and heat stroke may be more frequently associated with AED-SGAP combinations than with individual drugs. Researchers with expertise in in vitro DI studies or in vivo clinical studies using isotopes to explore drug clearance need to better study the SGAP metabolic pathways and how they change when inhibitors and inducers are added, particularly in the complicated conditions used in clinical practices such as adding both an inducer and an inhibitor to an SGAP (e.g., adding carbamazepine and fluoxetine to risperidone).

Grant and health agencies need to remember that pragmatic clinical trials are key in treating complex disorders such as epilepsy, schizophrenia and bipolar disorder, where polytherapy is the norm. Pharmaceutical RCTs do not substitute for long-term pragmatic trials that may better inform clinicians of the effectiveness of the various types of mono- and polytherapy frequently used in the real world of clinical practice. Pragmatic trials need to pay better attention to DI.

Progress in the next few years, if this research agenda is followed, should also be accompanied by a better continuous medical education on DIs and improvements in neuropsychopharmacology textbooks, so that clinicians begin to pay more attention to pharmacodynamic and pharmacokinetic DIs associated with the frequent co-prescription of AEDs and SGAPs. Well-educated clinicians will help move the 
research agenda by publishing DI case reports of unusual combinations and asking for more DI studies from pharmaceutical companies and researchers.

Acknowledgments: The authors acknowledge Lorraine Maw, M.A., and Margaret T. Susce, R.N., M.L.T. at the Mental Health Research Center at Eastern State Hospital, Lexington, KY, who helped in editing the article.

\section{Declaration of Interest}

The authors declare that no commercial organization had any role in the writing of this paper. $\mathrm{J}$ de Leon received researcher-initiated grants from Eli Lilly \& Co, Roche Molecular Systems, Inc. He has also received researcher-initiated grants in collaboration with Genomas Inc., from the NIH Small Business Innovation Research program. Additionally, he has been on the advisory boards of Bristol-Myers Squibb and AstraZeneca and has been supported by Roche Molecular Systems for one of his educational presentations. J de Leon has received lecture support in the past from Sandoz, Lundbeck, Pfizer, Eli Lilly \& Co., Janssen Pharmaceuticals, Bristol-Myers Squibb and Roche Molecular Systems, Inc. Furthermore, E Spina has participated in speakers/advisory boards and had lectures supported by AstraZeneca, Boheringer-Ingelheim, Eli Lilly \& Co, Janssen Pharmaceuticals, Lundbeck, Pfizer and Servier. C D'Arrigo and V Santoro have no conflicts of interest and have received no payment in the preparation of this manuscript. 


\section{Bibliography}

Papers of special note have been highlighted as either of interest $(\bullet)$ or of considerable interest $(\bullet \bullet)$ to readers.

1. Mula M, Monaco F. Antiepileptic-antipsychotic drug interactions: a critical review of the evidence. Clin Neuropharmacol 2002;25:280-9

2. Besag FMC, Berry D. Interactions between antiepileptic and antipsychotic drugs. Drug Saf 2006;29:95-118

- Prior comprehensive review that includes limited available data on first-generation antipsychotics.

3. Johannessen Landmark C. Antiepileptic drugs in non-epilepsy disorders: relations between mechanisms of action and clinical efficacy. CNS Drugs 2008;22:27-47

- Review of off-label uses of antiepileptics.

4. Marson AG, Al-Kharusi AM, Alwaidh M, et al. The SANAD study of effectiveness of valproate, lamotrigine, or topiramate for generalised and unclassifiable epilepsy: an unblinded randomised controlled trial. Lancet 2007; 369:1016-26

5. Marson AG, Al-Kharusi AM, Alwaidh M, et al. The SANAD study of effectiveness of carbamazepine, gabapentin, lamotrigine, oxcarbazepine, or topiramate for treatment of partial epilepsy: an unblended randomised controlled trial. Lancet 2007;369:1000-15

6. Maher AR, Maglione M, Bagley S, et al. Efficacy and comparative effectiveness of atypical antipsychotic medications for off-label uses in adults: a systematic review and meta-analysis. JAMA 2011;306:1359-69

- Review of off-label uses of second-generation antipsychotics.

7. Sandson NB, Marcucci C, Bourke DL, et al. An interaction between aspirin and valproate: the relevance of plasma protein displacement drug-drug interactions. Am J Psychiatry 2006;163:1891- 
- Good article if you want to learn about the occasional situations in which protein binding may be relevant in phenytoin and valproate drug interactions.

8. Johannesen Landmark C, Patsalos PN. Drug interactions involving the new second- and thirdgeneration antiepileptic drugs. Exp Rev Neurother 2010;10:119-40

-• Comprehensive review of second-generation antiepileptic drug interactions.

9. Spina E. Drug interactions. In: Treatment of Epilepsy, 3rd ed. Shorvon S, Perucca E, Engel J, (Eds.). Wiley-Blackwell Publishing Ltd, Oxford, 2009:361-77

10. Patsalos PN, Zakrzewska JM, Elyas AA. Dose dependent enzyme induction by oxcarbazepine? Eur J Clin Pharmacol 1990;39:187-8

11. Nallani SC, Glauser TA, Hariparsad N, et al. Dose-dependent induction of cytochrome P450 (CYP) 3A4 and activation of pregnane X receptor by topiramate. Epilepsia 2003;44:1521-8

12. Spina E, de Leon J. Metabolic drug interactions with newer antipsychotics: a comparative review. Basic Clin Pharmacol Toxicol 2007;100:4-22

-• Comprehensive review of second-generation antipsychotic drug interactions.

13. Rogawski MA, Löscher W. The neurobiology of antiepileptic drugs. Nat Rev Neurosci $2004 ; 5: 553-64$

- Comprehensive review article on antiepileptic pharmacodynamics of efficacy.

14. Brodie MJ. Antiepileptic drug therapy: the story so far. Seizure 2010;19:650-5

- Wise personal view of antiepileptics and their pharmacodynamics of efficacy.

15. Fountoulakis KN, Vieta E. Treatment of bipolar disorder: a systematic review of available data and clinical perspectives. Int J Neuropsychopharmacol 2008;11:999-1029

16. Harwood AJ, Agam G. Search for a common mechanism of mood stabilizers. Biochem Pharmacol 2003;66:179-89

17. Mula M, Pini S, Cassano GB. The role of anticonvulsant drugs in anxiety disorders: a critical review of the evidence. J Clin Psychopharmacol 2007;27:263-72 
18. Gadde KM, Franciscy DM, Wagner HR 2nd, et al. Zonisamide for weight loss in obese adults: a randomized controlled trial. JAMA. 2003;289:1820-5

19. Kramer CK, Leitão CB, Pinto LC, et al. Efficacy and safety of topiramate on weight loss: a metaanalysis of randomized controlled trials. Obes Rev 2011;12:e338-47

20. Kennedy GM, Lhatoo SD. CNS adverse events associated with antiepileptic drugs. CNS Drugs 2008;22:739-60

- Comprehensive review of antiepileptic brain safety.

21. Zaccara G, Gangemi PF, Cincotta M. Central nervous system adverse effects of new antiepileptic drugs. A meta-analysis of placebo-controlled studies. Seizure 2008;17:405-21

- Comprehensive meta-analysis of antiepileptic brain safety.

22. Stephen LJ, Brodie MJ. Pharmacotherapy of epilepsy: newly approved and developmental agents. CNS Drugs 2011;25:89-107

23. Mattson RH. Cognitive, affective, and behavioral side events in adults secondary to antiepileptic drug use. Rev Neurol Dis 2004;1(Suppl 1):S10-7

24. Mula M, Trimble MR. Antiepileptic drug-induced cognitive adverse effects: potential mechanisms and contributing factors. CNS Drugs 2009;23:121-37

25. Sirven JI, Fife TD, Wingerchuk DM, et al. Second-generation antiepileptic drugs' impact on balance: a meta-analysis. Mayo Clin Proc 2007;82:40-7

26. Beydoun A, D'Souza J, Hebert D, Doty P. Lacosamide: pharmacology, mechanisms of action and pooled efficacy and safety data in partial-onset seizures. Expert Rev Neurother 2009;9:33-42

27. Mula M, Sander JW. Negative effects of antiepileptic drugs on mood in patients with epilepsy. Drug Safety 2007;30:555-67

28. Brandt C, Fueratsch N, Boehme V et al. Development of psychosis in patients with epilepsy treated with lamotrigine: report of six cases and review of the literature. Epilepsy Behav 2007;11:133-9 
29. Brodtkorb E, Mula M. Optimizing therapy of seizures in adult patients with psychiatric comorbidity. Neurology 2006;67(Suppl 4):S39-44

30. White JR, Walczak TS, Marino SE, et al. Zonisamide discontinuation due to psychiatric and cognitive adverse events: a case-control study. Neurology 2010;75:513-8

31. Dinkelacker V, Dietl T, Widman G, et al. Aggressive behavior of epilepsy patients in the course of levetiracetam add-on therapy: report of 33 mild to severe cases. Epilepsy Behav 2003;4:537-47

32. Boussemart T, Flurin V, Labay-Bruneau F, et al. Heat stroke and topiramate. Arch Pediatr $2008 ; 15: 416-8$

33. Shimizu T, Yamashita Y, Satoi M, et al. Heat stroke-like episode in a child caused by zonisamide. Brain Dev 1997;19:366-8

34. Nolla-Salas J, Gracia MP, Martín JC, et al. Heatstroke during topiramate treatment. Med Clin (Barc) 2007;128:677-8

35. Gerstner T, Büsing D, Bell N, et al. Valproic acid-induced pancreatitis: 16 new cases and a review of the literature. J Gastroenterol 2007;42:39-48

36. Buzan RD, Firestone D, Thomas M, et al. Valproate-associated pancreatitis and cholecystitis in six mentally retarded adults. J Clin Psychiatry 1995;56:529-32

- Small study but raises the question that pancreatitis may not be rare in institutionalized adults with intellectual disabilities.

37. Yatham LN, Goldstein JM, Vieta E, et al. Atypical antipsychotics in bipolar depression: potential mechanisms of action. J Clin Psychiatry 2005;66(Suppl 5):40-8

38. Nelson JC, Papakostas GI. Atypical antipsychotic augmentation in major depressive disorder: a meta-analysis of placebo-controlled randomized trials. Am J Psychiatry 2009;166:980-91

39. Blier P, Szabo ST. Potential mechanisms of action of atypical antipsychotic medications in treatment-resistant depression and anxiety. J Clin Psychiatry 2005;66:30-40 
40. Prieto E, Micó JA, Meana JJ, et al. Neurobiological bases of quetiapine antidepressant effect in the bipolar disorder. Actas Esp Psiquiatr 2010;38:22-32

41. Stahl SM, Shayegan DK. The psychopharmacology of ziprasidone: receptor-binding properties and real-world psychiatric practice. J Clin Psychiatry 2003;64 Suppl 19:6-12

42. Sachs GS, Ice KS, Chappell PB, et al. Efficacy and safety of adjunctive oral ziprasidone for acute treatment of depression in patients with bipolar I disorder: a randomized, double-blind, placebocontrolled trial. J Clin Psychiatry 2011;72:1413-22

43. Buchanan RW, Kreyenbuhl J, Kelly DL, et al. The 2009 schizophrenia PORT psychopharmacological treatment recommendations and summary statements. Schizophr Bull 2010;36:71-93

\section{- Comprehensive review of antipsychotic efficacy and safety in schizophrenia.}

44. Gonzalez JM, Thompson PM, Moore TA. Review of the safety, efficacy, and side effect profile of asenapine in the treatment of bipolar 1 disorder. Patient Prefer Adherence 2011;5:333-41

45. Weiden PJ, Cutler AJ, Polymeropoulos MH, et al. Safety profile of iloperidone: a pooled analysis of 6-week acute-phase pivotal trials. J Clin Psychopharmacol 2008;28(Suppl 1):S12-9

46. Samalin L, Garnier M, Llorca PM. Clinical potential of lurasidone in the management of schizophrenia. Ther Clin Risk Manag 2011;7:239-50

47. Cutler AJ, Kalali AH, Weiden PJ, et al. Four-week, double-blind, placebo- and ziprasidonecontrolled trial of iloperidone in patients with acute exacerbations of schizophrenia. J Clin Psychopharmacol 2008;28:S20-8

48. de Leon J, Sandson NB, Cozza KL. A preliminary attempt to personalize risperidone dosing using drug-drug interactions and genetics: part I. Psychosomatics 2008;49:258-70

49. Kane JM, Sharif ZA. Atypical antipsychotics: sedation versus efficacy. J Clin Psychiatry 2008;69:18-31 
50. Weiden PJ, Preskorn SH, Fahnestock PA, et al. Translating the psychopharmacology of antipsychotics to individualized treatment for severe mental illness: a roadmap. J Clin Psychiatry 2007;68(Suppl 7):1-48

51. de Leon J. Paying attention to pharmacokinetic and pharmacodynamic mechanisms to progress in the area of anticholinergic use in geriatric patients. Curr Drug Metab 2011;12:635-46

52. Thornton AE, Van Snellenberg JX, Sepehry AA, et al. The impact of atypical antipsychotic medications on long-term memory dysfunction in schizophrenia spectrum disorder: a quantitative review. J Psychopharmacol 2006;20:335-46

53. Alper K, Schwartz KA, Kolts RL, et al. Seizure incidence in psychopharmacological clinical trials: an analysis of Food and Drug Administration (FDA) summary basis of approval reports. Biol Psychiatry 2007;62:345-54

54. Torta R, Monaco F. Atypical antipsychotics and serotoninergic antidepressants in patients with epilepsy: pharmacodynamic considerations. Epilepsia 2002;43Supp1 2:8-13

55. Serretti A, Chiesa A. A meta-analysis of sexual dysfunction in psychiatric patients taking antipsychotics. Int Clin Psychopharmacol 2011;26:130-40

56. Curran MP, Perry CM. Amisulpride: a review of its use in the management of schizophrenia. Drugs 2001;61:2123-50

57. Citrome L. Iloperidone, asenapine, and lurasidone: a brief overview of 3 new second-generation antipsychotics. Postgrad Med 2011;123:153-62

58. Citrome L. Lurasidone for schizophrenia: a review of the efficacy and safety profile for this newly approved second-generation antipsychotic. Int J Clin Pract 2011;65:189-210

59. Martin-Latry K, Goumy MP, Latry P, et al. Psychotropic drug use and risk of heat-related hospitalisation. Eur Psychiatry 2007;22:335-8

- If you are not familiar with heat stroke, you may want to read this study. Be aware that this article does not describe that topiramate or zonisamide can induce heat strokes. 
60. Citrome L, Macher JP, Salazar DE, et al. Pharmacokinetics of aripiprazole and concomitant carbamazepine. J Clin Psychopharmacol 2007;27:279-83

61. Nakamura A, Mihara K, Nagai G, et al. Pharmacokinetic and pharmacodynamic interactions between carbamazepine and aripiprazole in patients with schizophrenia. Ther Drug Monit $2009 ; 31: 575-8$

62. Castberg I, Spigset O. Effect of comedication on the serum level of aripiprazole: evidence from a routine therapeutic drug monitoring service. Pharmacopsychiatry 2007;40:107-10

63. Jerling M, Lindstrom L, Bondesson U, Bertilsson L. Fluvoxamine inhibition and carbamazepine induction of the metabolism of clozapine: evidence from a therapeutic drug monitoring service. Ther Drug Monit 1994;16:368-74

64. Tiihonen J, Bartiainen H, Hakola P. Carbamazepine-induced changes in plasma levels of neuroleptics. Pharmacopsychiatry 1995;28:26-8

65. Lucas RA, Gilfillan DJ, Bergstrom RF. A pharmacokinetic interaction between carbamazepine and olanzapine: observations on possible mechanisms. Eur J Clin Pharmacol 1998;54:639-43

66. Olesen OV, Linnet K. Olanzapine serum concentrations in psychiatric patients given standard doses: the influence of comedication. Ther Drug Monit 1999;21:87-90

67. Linnet K, Olesen OV. Free and glucuronidated olanzapine serum concentrations in psychiatric patients: influence of carbamazepine comedication. Ther Drug Monit 2002;24:512-7

68. Skogh E, Reis M, Dahl M, et al. Therapeutic drug monitoring data on olanzapine and its Ndemethyl metabolite in the naturalistic clinical setting. Ther Drug Monit 2002;24:518-26

69. Botts S, Diaz FJ, Santoro V, et al. Estimating the effects of co-medications on plasma olanzapine concentrations by using a mixed model. Progr Neuro-Psychopharmacol Biol Psychiatry $2008 ; 32: 1453-8$ 
70. Grimm SW, Richtand NM, Winter HR, et al. Effects of cytochrome P450 3A modulators ketoconazole and carbamazepine on quetiapine pharmacokinetics. Br J Clin Pharmacol $2006 ; 61: 58-6$

71. Hasselstrom J, Linnet K. Quetiapine serum concentrations in psychiatric patients. Ther Drug Monit 2004;26:486-91

72. Castberg I, Skogvoll E, Spigset O. Quetiapine and drug interactions: evidence from a routine therapeutic drug monitoring service. J Clin Psychiatry 2007;68:1540-5

73. Santoro V, D'Arrigo C, Migliardi G, et al. Therapeutic drug monitoring of quetiapine: effect of coadministration with antiepileptic drugs in patients with psychiatric disorders. Open Clin Chem J $2008 ; 1: 17-21$

74. Wittman M, Hauser H, Köstlbacher A, et al. Individual clearance and therapeutic drug monitoring of quetiapine in clinical practice. Neuroendocrinol Lett 2010;31:203-7

75. Nicki-Jockschat T, Paulzen M, Schneider F, et al. Drug interaction can lead to undetectable serum concentrations of quetiapine in the presence of carbamazepine. Clin Neuropharmacol 2009;32:5

76. de Leon J, Bork J. Risperidone and cytochrome P450 3A [letter]. J Clin Psychiatry 1997;58:450

77. Spina E, Avenoso A, Facciolà G, et al. Plasma concentrations of risperidone and 9-hydroxyrisperidone effect of comedication with carbamazepine or valproate. Ther Drug Monit $2000 ; 22: 481-5$

78. Ono S, Mihara K, Suzuki A, et al. Significant pharmacokinetic interaction between risperidone and carbamazepine: its relationship with CYP2D6 genotypes. Psychopharmacology 2002;162:504

79. Spina E, Scordo MG, Avenoso A, et al. Adverse drug interaction between risperidone and carbamazepine in a patient with chronic schizophrenia and deficient CYP206. J Clin Psychopharmacol 2001;21:108-9 
80. Miceli JJ, Anziano RJ, Robarge L, et al. The effect of carbamazepine on the steady-state pharmacokinetics of ziprasidone in healthy volunteers. Br J Clin Pharmacol 2000;49:65S-70S

81. Mula M, Monaco F. Carbamazepine-risperidone interaction in patients with epilepsy. Clin Neuropharmacol 2002;25:97-100

82. Fitzgerald B, Okos A. Elevation of carbamazepine-10:11-epoxide by quetiapine. Pharmacother 2002;22:1500-3

83. Kossen M, Selten JP, Kahn RS. Elevated clozapine plasma level with lamotrigine [letter]. Am J Psychiatry 2001;158:1930

84. Tiihonen J, Hallikainen T, Ryynanen OP, et al. Lamotrigine in treatment-resistant schizophrenia: a randomized placebo-controlled crossover trial. Biol Psychiatry 2003;54:1241-8

85. Spina E, D’Arrigo C, Migliardi G, et al. Effect of adjunctive lamotrigine treatment on the plasma concentrations of clozapine, risperidone and olanzapine in patients with schizophrenia or bipolar disorder. Ther Drug Monit 2006;28:599-602

86. Jann MW, Hon YY, Shamsi SA, et al. Lack of pharmacokinetic interaction between lamotrigine and olanzapine in healthy volunteers. Pharmacotherapy 2006;26:627-33

87. Sidhu J, Job S, Bullman J, et al. Pharmacokinetics and tolerability of lamotrigine and olanzapine coadministered to healthy subjects. Br J Clin Pharmacol 2006;61:420-6

88. Bienentreu SD, Kronmuller KTH. Increase in risperidone plasma level with lamotrigine. Am J Psychiatry 2005;162:811-2

89. Reimers A, Skogvoll E, Sund JK, et al. Drug interaction between lamotrigine and psychoactive drugs. J Clin Psychopharmacol 2005;25:342-8

90. Schieber FC, Boulton DW, Balch AH, et al. A non-randomized study to investigate the effects of the atypical antipsychotic aripiprazole on the steady-state pharmacokinetics of lamotrigine in patients with bipolar I disorder. Hum Psychopharmacol Clin Exp 2009;24:145-52 
91. Miller DD. Effect of phenytoin on plasma clozapine concentrations in two patients. J Clin Psychiatry 1991;52:23-5

92. Lane HY, Su KP, Chang WH et al. Elevated plasma clozapine concentrations after phenobarbital discontinuation. J Clin Psychiatry 1998;59:131-3

93. Facciolà G, Avenoso A, Spina E, Perucca E. Inducing effect of phenobarbital on clozapine metabolism in patients with chronic schizophrenia. Ther Drug Monit 1998;20:628-30

94. Wong YW, Yeh C, Thyrum PT. The effects of concomitant phenytoin administration on the steady-state pharmacokinetics of quetiapine. J Clin Psychopharmacol 2001;21:89-93

95. Muscatello MR, Pacetti M, Cacciola M, et al. Plasma concentrations of risperidone and olanzapine during coadministration with oxcarbazepine. Epilepsia 2005;46:771-4

96. Migliardi G, D’Arrigo C, Santoro V, et al. Effect of topiramate on plasma concentrations of clozapine, olanzapine, risperidone, and quetiapine in patients with psychotic disorders. Clin Neuropharmacol 2007;30:107-13

97. Cerveny L, Svecova L, Anzenbacherova E, et al. Valproic acid induces CYP3A4 and MDR1 gene expression by activation of constitutive androstane receptor and pregnane $\mathrm{X}$ receptor pathways. Drug Metab Dispos 2007;35:1032-41

98. Citrome L, Josiassen R, Bark N, et al. Pharmacokinetics of aripiprazole and concomitant lithium and valproate. J Clin Pharmacol 2005;45:89-93

99. Diaz FJ, Santoro V, Spina E, et al. Estimating the size of the effects of co-medications on plasma clozapine concentrations using a model that controls for clozapine doses and confounding variables. Pharmacopsychiatry 2008;41:81-91

100. Centorrino F, Baldessarini RJ, Kando J, et al. Serum concentrations of clozapine and its metabolites: effects of cotreatment with fluoxetine or valproate. Am J Psychiatry 1994;151:123-5 
101. Facciolà G, Avenoso A, Scordo MG, et al. Small effects of valproic acid on the plasma concentrations of clozapine and its major metabolites in patients with schizophrenic or affective disorders. Ther Drug Monit 1999;21:341-5

102. Wong JO, Leung SP, Mak T, et al. Plasma clozapine levels and clinical response in treatment-refractory Chinese schizophrenic patients. Prog Neuro-Psychopharmacol Biol Psychiatry 2006;30:251-64

103. Finley P, Warner D. Potential impact of valproic acid therapy on clozapine disposition. Biol Psychiatry 1994;36:487-8

104. Gex-Fabry M, Balant-Gorgia AE, Balant LI. Therapeutic drug monitoring of olanzapine: the combined effect of age, gender, smoking, and comedication. Ther Drug Monit 2003;25:46-53

105. Bergemann N, Kress KR, Abu-Tair F, et al. Valproate lowers plasma concentration of olanzapine. J Clin Psychopharmacol 2006;26:432-4

106. Spina E, D’Arrigo C, Santoro V, et al. Effect of valproate on olanzapine plasma concentrations in patients with bipolar or schizoaffective disorder. Ther Drug Monit 2009;31:75863

107. de Leon J, Diaz F, Spina E. Pharmacokinetic drug-drug interactions between olanzapine and valproate need to be better studied [letter]. J Clin Psychiatry 2010;71:957-8

108. Aichhorn W, Marksteiner J, Walch T, et al. Influence of age, gender, body weight and valproate co-medication on quetiapine plasma concentrations. Int Clin Psychopharmacol $2006 ; 21: 81-5$

109. Winter HR, DeVane CL, Figueroa C, et al. Open-label steady-state pharmacokinetic drug interaction study on co-administered quetiapine fumarate and divalproex sodium in patients with schizophrenia, schizoaffective disorder, or bipolar disorder. Hum Psychopharmacol Clin Exp 2007;22:469-76 
110. Ravindran A, Silverstone P, Lacroix D, et al. Risperidone does not affect steady-state pharmacokinetics of divalproex sodium in patients with bipolar disorder. Clin Pharmacokinet 2004;43:733-40

111. Gerrits MG, de Greef R, Dogterom P, et al. Valproate reduces the glucuronidation of asenapine without affecting asenapine plasma concentrations. J Clin Pharmacol 2011: published online May 132011 doi: 10.1177/00912700114040

112. Albers LJ, Musenga A, Raggi MA. Iloperidone: a new benzisoxazole atypical antipsychotic drug. Is it novel enough to impact the crowded atypical antipsychotic market? Expert Opin Investig Drugs 2008;17:61-75

113. Meyer JM, Loebel AD, Schweizer E. Lurasidone: a new drug in development for schizophrenia. Expert Opin Investig Drugs 2009;1:1715-26

114. Ketter TA. Monotherapy versus combined treatment with second-generation antipsychotics in bipolar disorder. J Clin Psychiatry 2008;69 Suppl 5:9-15

115. Canitano R. Clinical experience with topiramate to counteract neuroleptic induced weight gain in 10 individuals with autistic spectrum disorders. Brain Dev 2005;27:228-32

116. US Department of Mental Health and Human Services. Statistical review and evaluation: antiepileptic drugs and suicidality, 2005. Available at http://www.fda.gov/ohrms/dockets/ac/08/briefing/2008-4372b1-01-FDA.pdf [Last accessed 11 January 2012]

117. Bell GS, Mula M, Sander JW. Suicidality in people taking antiepileptic drugs: What is the evidence? CNS Drugs 2009;23:281-92

118. Arana A, Wentworth CE, Ayuso-Mateos JL, et al. Suicide-related events in patients treated with antiepileptic drugs. N Engl J Med 2010;363:542-51

119. Hesdorffer DC, Berg AT, Kanner AM. An update on antiepileptic drugs and suicide: are there definitive answers yet? Epilepsy Curr 2010;10:137-45 
120. Harris EC, Barraclough B. Suicide as an outcome for mental disorders. A meta-analysis. Br J Psychiatry 1997;170:205-28

121. Meltzer HY, Bonaccorso S, Bobo WV, et al. A 12-month randomized, open-label study of the metabolic effects of olanzapine and risperidone in psychotic patients: influence of valproic acid augmentation. J Clin Psychiatry 2011: published online Jul 12 2011doi:10.4088/JCP.10m05997

122. Rhaman A, Mican LM, Fischer C, et al. Evaluating the incidence of leukopenia and neutropenia with valproate, quetiapine, or the combination in children and adolescents. Ann Pharmacother 2009;43:822-30 


\section{OTHER PHARMACOKINETIC ISSUES}

\section{P-GLYCOPROTEIN (P-gp)}

1) P-gp plays a central role in the absorption, distribution and excretion of a wide variety of drugs.

2) P-gp is a multidrug efflux transporter, encoded by the MDR1 gene (or ABCB1), highly expressed in the intestine, brain, liver and kidney.

3) It acts as a natural defense mechanism against several drugs by limiting their absorption from the gut and penetration into the brain, and promoting their elimination in the bile and urine.

4) Like metabolizing enzymes, P-gp activity can be inhibited or induced by other agents, altering the concentration of substrate drug in blood and brain. In particular, some antiepileptic drugs (AED) pharmacokinetic drug-drug interactions (DIs) currently attributed to enzyme induction may, in fact, be due to overexpression of such transporters resulting in the affected drug having limited gastrointestinal absorption or reduced penetration to the brain, or enhanced elimination in the bile and urine.

5) Second-generation antipsychotics (SGAPs) have been reported to show various degrees of inhibitory effects on P-gp activity.

6) In summary, P-gp activity is probably relevant in explaining AED and SGAP DIs but our current knowledge is too limited to determine P-gp's importance.

\section{PROTEIN BINDING}

1) Theoretically, protein binding displacement interactions may occur between AED and SGAPs.

2) Competition between two drugs for binding sites on plasma proteins may elevate levels of the displaced drug's free fraction in plasma or tissue, thereby potentially increasing its pharmacological effects.

3) However, in most circumstances this type of DI is not clinically relevant since the displaced drug is diluted into a large volume of distribution or is rapidly cleared, and the unbound, pharmacologically active concentration remains almost unchanged.

4) In quantitative terms, displacement interactions may only be important for drugs that are highly bound to plasma proteins $(>90 \%)$. A number of SGAPs are extensively bound to plasma proteins (Table 2), while among AEDs only phenytoin, valproate and tiagabine belong to this category (Table 1).

5) Clinically relevant DIs due to increased free concentrations have occasionally been described for phenytoin and valproate [7], but the other AEDs or anti-inflammatory drugs usually cause increased valproate or phenytoin free concentrations.

6) No clear cases of SGAPs increasing free phenytoin or valproate concentrations have been published in the literature.

Figure 1. Other pharmacokinetic issues. 


\section{PHARMACODYNAMICS FOR ANTIEPILEPTIC EFFICACY}

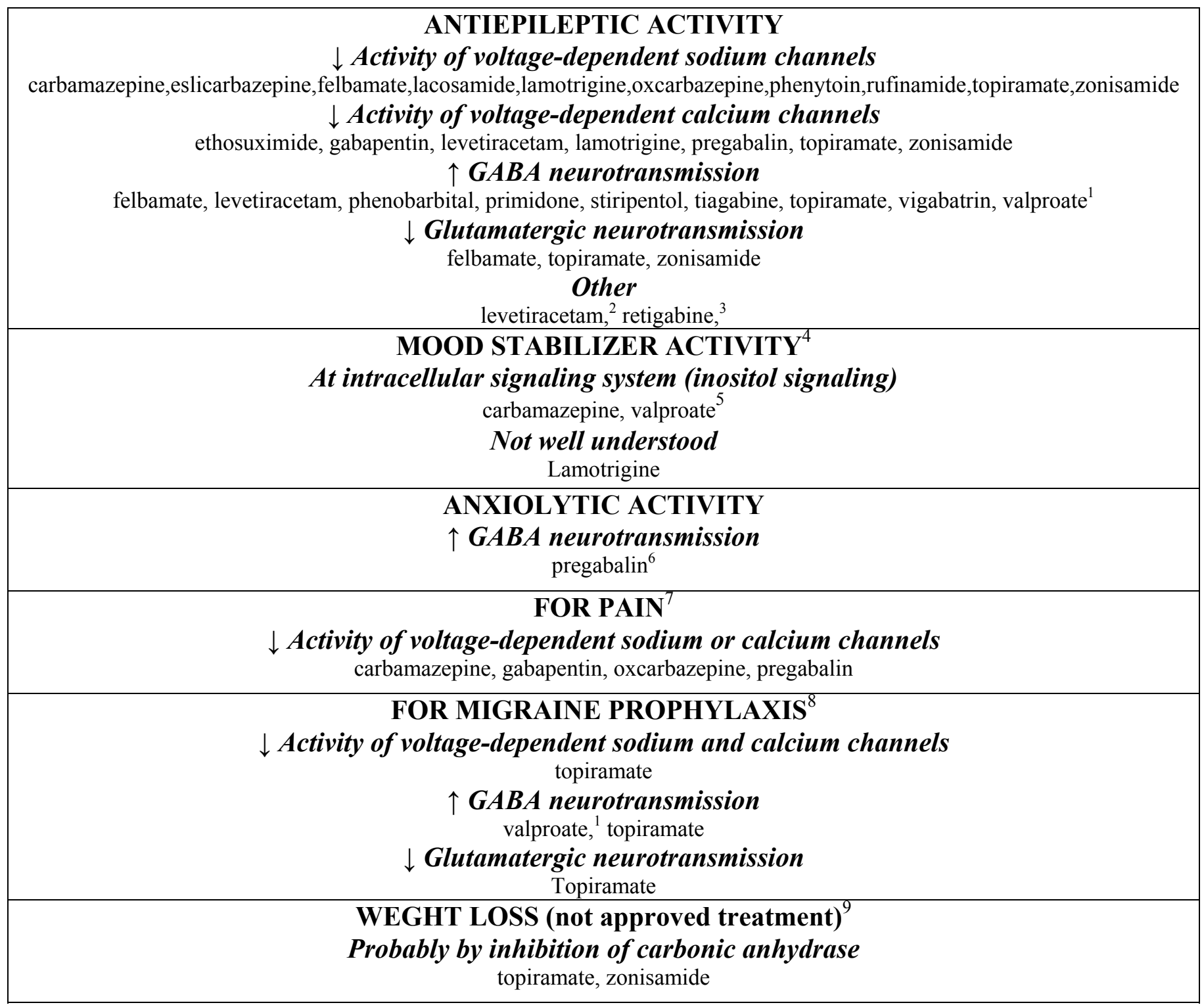

Figure 2. Pharmacodynamics for antiepileptic efficacy.

ADRs: adverse drug reactions; AED: antiepileptic drug; RTC: randomized clinical trial.

${ }^{1}$ There is general agreement that valproate acts mainly by increasing GABAergic neurotransmission but a more precise description might be that valproate has complex actions, since valproate may act at the voltage-dependent sodium and calcium channels [13].

${ }^{2}$ Levetiracetam has complex actions including one that appears specific to this compound: binding to synaptic vesicle protein $2 \mathrm{~A}$ interfering with the recycling of synaptic vesicles and the release of a range of neurotransmitters [14].

${ }^{3}$ Retigabine appears to open potassium channels [14].

${ }^{4}$ AEDs approved in the US for bipolar disorder include: i) valproate for mania; ii) carbamazepine for the treatment of acute manic and mixed episodes of bipolar disorder; and iii) lamotrigine for prophylaxis, particularly of depressive phases [15]. Treatment guidelines also consider: 1) valproate monotherapy or adjunctive for bipolar depression or prophylaxis, ii) carbamazepine monotherapy or adjunctive for prophylaxis, and iii) lamotrigine monotherapy or adjunctive for bipolar depression [15]. Gabapentin, lamotrigine and topiramate mania RCTs were negative [15]. Oxcarbazepine bipolar disorder RCTs appear promising. There are no published RCTs for eslicarbazepine, levetiracetam or zonisamide. 
${ }^{5}$ Valproate is a histone deacetylase inhibitor. It is not known whether this action contributes to its mood stabilizing properties or not [16].

${ }^{6}$ Pregabalin is approved for generalized anxiety disorder in Europe but not in the US. Other AEDs may have antianxiety properties [17].

${ }^{7}$ In the US approved drugs include: i) carbamazepine for trigeminal neuralgia, ii) gabapentin for postherpetic neuralgia, and iii) pregabalin for postherpetic neuralgia and diabetic neuropathic pain. Lacosamide is being studied in RCTs for diabetic neuropathic pain. Oxcarbazepine is usually considered an alternative for trigeminal neuralgia when patients cannot tolerate carbamazepine. Johannessen Landmark considers other AEDs, including levetiracetam, lamotrigine and phenytoin, as acceptable treatments for neuropathic pain [3].

${ }^{8}$ In the US, the only AEDs approved for migraine prophylaxis are topiramate and valproate.

${ }^{9}$ Topiramate and zonisamide treatments are frequently associated with weight loss but are not approved for that indication in the US. These two drugs were associated with too many ADRs in obesity RCTs [18, 19]. 


\section{PHARMACODYNAMICS FOR ANTIEPILEPTIC SAFETY}

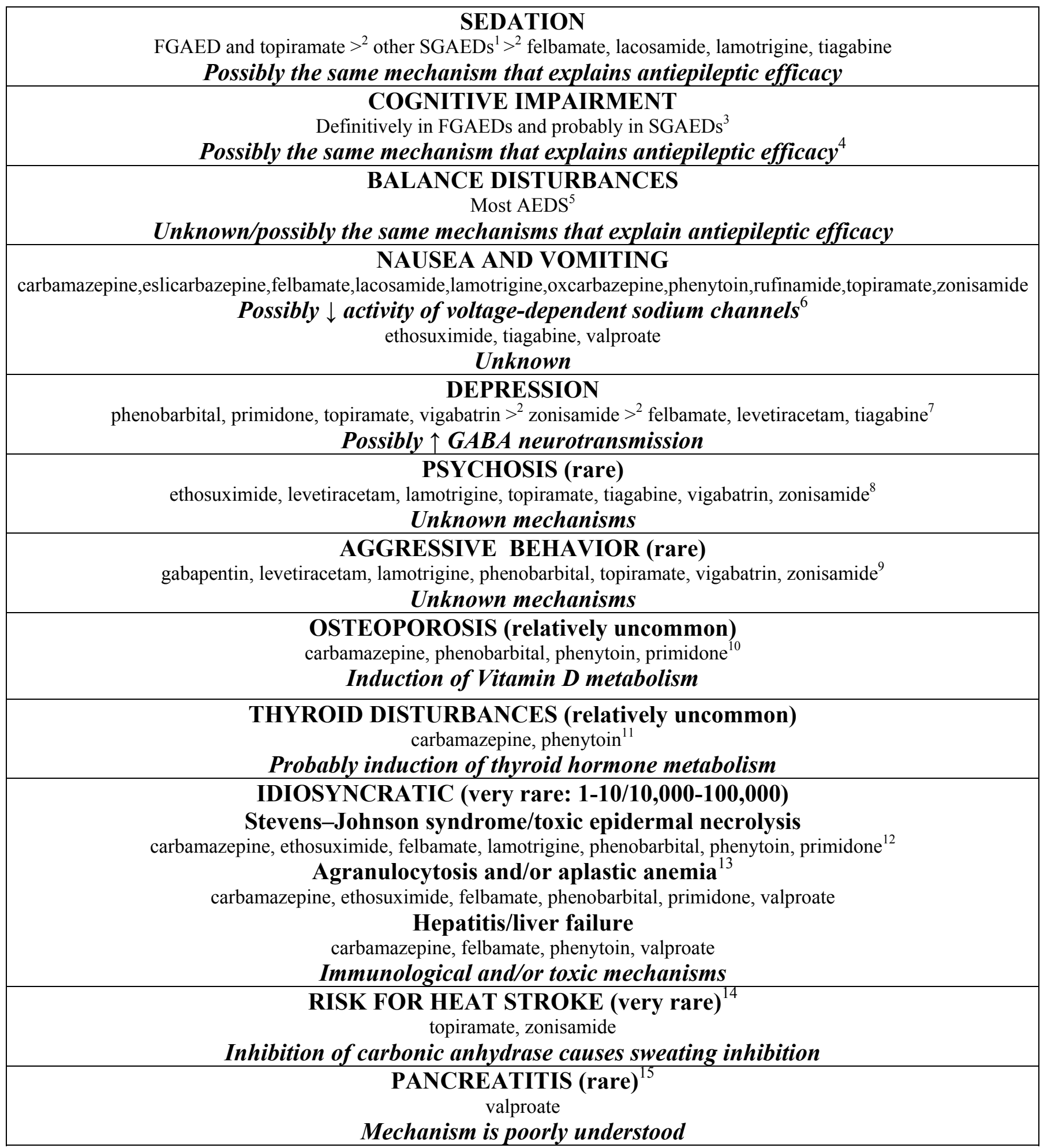

Figure 3. Pharmacodynamics for antiepileptic safety.

ADR: adverse drug reaction; AED: antiepileptic drug; FGAED: first-generation antiepileptic drug; SGAED: second-generation antiepileptic drug.

${ }^{1}$ All FGAEDs are definitively associated with sedation [20]. A meta-analysis found that most SGAEDs (gabapentin, levetiracetam, pregabalin, topiramate and zonisamide) were associated with somnolence when compared with placebo [20]. Other SGAEDs including oxcarbazepine, vigabatrin [20], 
eslicarbazepine, retigabine, and rufinamide [21] also are probably associated with sedation. Felbamate, lacosamide, lamotrigine, and tiagabine appear to be associated with low sedation risk [20, 22].

${ }^{2}$ Drugs preceding ">" will produce this ADR more frequently than drugs following ">".

${ }^{3}$ FGAEDs are associated with cognitive impairment in studies using neuropsychological testing. There are few neuropsychological studies on SGAEDs. Different authors agree that phenobarbital has the worst cognitive profile among FGAEDs, and topiramate among SGAEDs, but disagree on the relative impairment associated with specific compounds and how topiramate compares with FGAEDs [23, 24]. Vigabatrin can be associated with visual defect fields.

${ }^{4}[24]$

${ }^{5}$ FGAEDs (except for ethosuximide) are definitively associated with ataxia and other balance disturbances [20]. A meta-analysis indicated most SGAEDs (lamotrigine, oxcarbazepine, pregabalin, tiagabine, topiramate and zonisamide) are associated with balance disturbances while gabapentin and levetiracetam may not be [25]. Other AEDs including felbamate, vigabatrin [20], eslicarbazepine, lacosamide, retigabine, and rufinamide [25] are probably associated with balance disturbances.

${ }^{6}$ Beydoun et al. proposed that nausea and vomiting may be explained by decreased activity of voltagedependent sodium channels [26]. Review articles focused on AED pharmacodynamics do not comment on possible mechanisms that may explain AED-induced nausea and vomiting.

${ }^{7}$ Different reviews provide different frequencies of each AED-induced depression. A comprehensive review described frequencies $>10 \%$ for phenobarbital, primidone, topiramate and vigabatrin; $7 \%$ for zonisamide in high doses; $\leq 4 \%$ for felbamate, levetiracetam and tiagabine; and $<1 \%$ for the rest of the studied AEDs. On the other hand, carbamazepine, lamotrigine, oxcarbazepine and valproate may have antidepressant properties in patients with epilepsy [27].

${ }^{8}$ It is difficult to assess when psychosis is really an AED ADR rather than a manifestation of the underlying or associated illnesses. AEDs associated with psychosis include levetiracetam, lamotrigine, topiramate, tiagabine, vigabatrin [28], ethosuximide [29] and zonisamide [30]. Studies using lamotrigine and topiramate in bipolar disorder do not describe increased psychotic symptoms.

${ }^{9}$ It is difficult to assess when aggressive behavior is really an AED ADR rather than anderlying or associated illness. AEDs associated with irritability or aggression are gabapentin, levetiracetam, lamotrigine, phenobarbital, topiramate, vigabatrin [31] and zonisamide [30].

${ }^{10}$ Oxcarbazepine may also be associated with osteoporosis risk. Valproate also appears to be associated with osteoporosis but the mechanism is not well understood.

${ }^{11}$ Oxcarbazepine may be associated with mild thyroid disturbances.

${ }^{12}$ Other AEDs less clearly associated with Stevens-Johnson syndrome/toxic epidermal necrolysis are oxcarbazepine, valproate and zonisamide.

${ }^{13}$ Valproate is frequently associated with thrombocytopenia and more rarely, with neutropenia. Valproateinduced thrombocytopenia appears to be dose-related and explained by direct toxic mechanism rather than by immunological mechanism.

${ }^{14}$ The literature describes most cases of heat stroke associated with topiramate [32] or zonisamide [33] as occurring in children but adult cases during a heat wave have been described [34].

${ }^{15}$ The literature describes valproate-induced pancreatitis as very rare. A comprehensive review in Germany indicated that milder cases are much more common than the literature suggests [35]. In a review of all 5 years of data from a facility for 322 adults with intellectual disabilities, the frequency of pancreatitis in patients taking valproate was not rare; it was $7 \%(5 / 72$ patients) [36]. The first author has similar experience that pancreatitis is not rare in these facilities. 


\section{PHARMACODYNAMICS FOR SGAP EFFICACY}

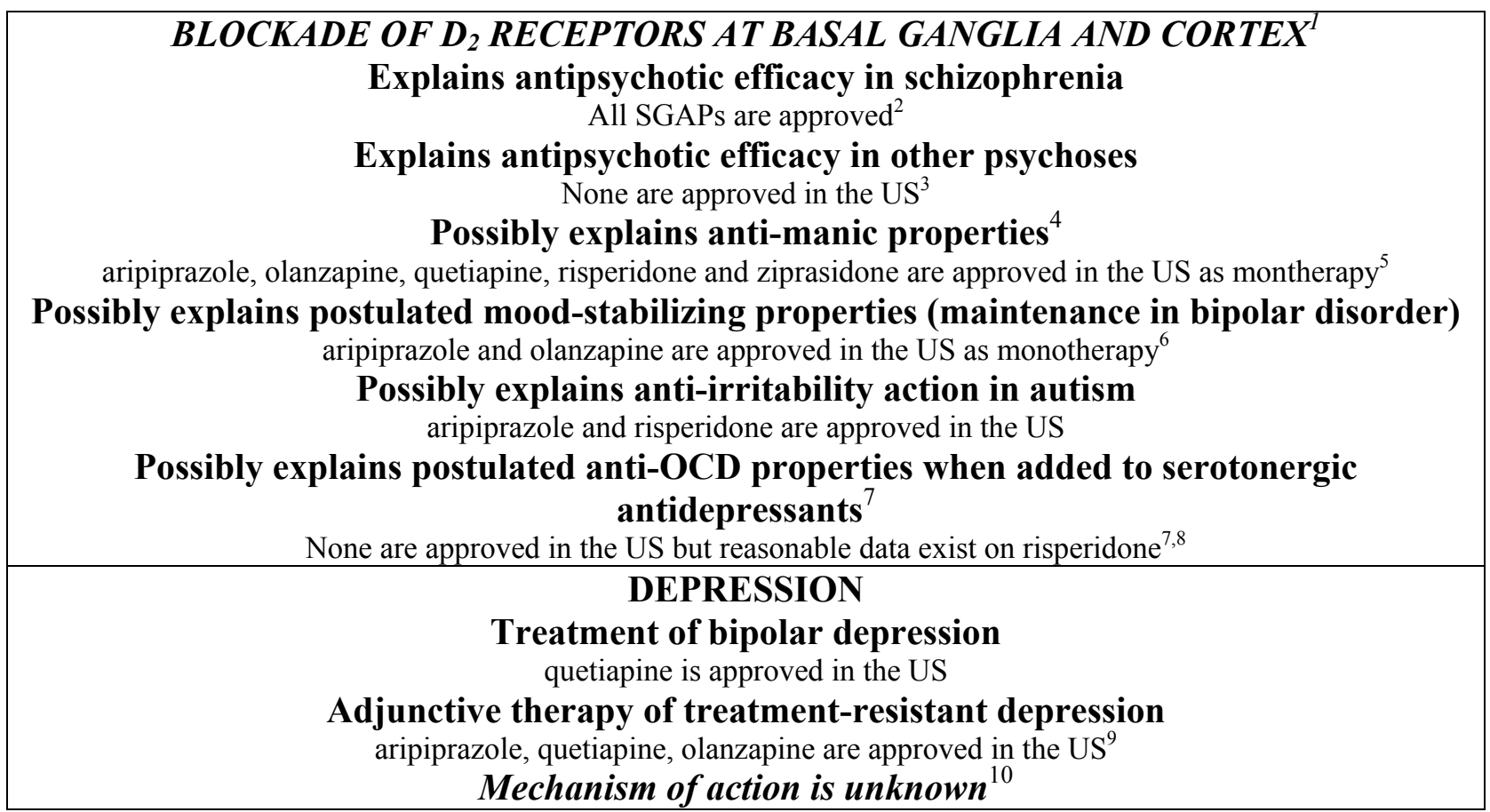

Figure 4. Pharmacodynamics of efficacy for second-generation antipsychotics

5-HT: serotonin receptor; AP: antipsychotic; D: dopamine receptor; RCT: randomized clinical trial; SGAP: second-generation antipsychotic.

${ }^{1}$ All APs are $\mathrm{D}_{2}$ antagonists except for aripiprazole which is a partial agonist (some authors have proposed that occasionally aripiprazole can be associated with worsening of psychosis). Brain imaging studies indicate that antipsychotic efficacy may be associated with $\mathrm{D}_{2}$ blockade at the basal ganglia and cortex. ${ }^{2}$ Amisulpride is approved in Europe but has not been studied for approval in the US.

${ }^{3}$ No SGAP is approved for psychosis (or behaviors) in dementing illness. Paliperidone is approved for schizoaffective disorder in the US.

${ }^{4}[37]$

${ }^{5}$ Aripiprazole, asenapine, quetiapine, risperidone, and olanzapine have been approved for adjunctive therapy with lithium or valproate. Other SGAPs have not been studied in RCTs. ${ }^{6}$ Quetiapine has been approved for adjunctive therapy with lithium or valproate.

${ }^{7}[6]$

$8[6]$

${ }^{9}$ Olanzapine is approved in combination with fluoxetine. Risperidone had some positive results in RCTs [38].

${ }^{10}$ The mechanisms proposed in bipolar depression include: i) a high ratio between $5-\mathrm{HT}_{2 \mathrm{~A}} / \mathrm{D}_{2}$ receptors [37], and ii) a possible role for 5- $\mathrm{HT}_{2 \mathrm{~A}}$ or $\alpha_{2}$ blockade [39]. Common mechanisms proposed for adjunctive treatment in major depressive disorder include $5-\mathrm{HT}_{2 \mathrm{~A}}$ blockade that may be shared by approved SGAPs [38]. Specific mechanism include: i) 5-HT 1 A partial agonism only for aripiprazole [38]; and 5-HT2 ${ }_{\mathrm{C}}$ antagonist and inhibition of noradrenaline transporter by norquetiapine, the main active metabolite of quetiapine [40]. Ziprasidone at clinical dose blocks reuptake of serotonin, noradrenaline and dopamine [41], which may suggest potential for antidepressant properties but the only published ziprasidone trial in bipolar depression indicated this compound had no more efficacy than placebo [42]. 
PHARMACODYNAMICS FOR SGAP SAFETY

BRAIN

EXTRAPYRAMIDAL SYMPTOMS

amisulpride,paliperidone, risperidone $>^{1}$ asenapine, iloperidone, lurasidone, olanzapine,ziprasidone $>{ }^{1}$ quetiapine $>{ }^{1}$ clozapine ${ }^{2}$ Blockade of $D_{2}$ receptors at nigrostriatal system ${ }^{2}$

\section{HYPERPROLACTINEMIA}

amisulpride,paliperidone, risperidone $>^{1}$ asenapine, iloperidone, lurasidone, olanzapine,ziprasidone $>^{1}$ quetiapine,clozapine $>1$ aripiprazole ${ }^{3}$

Blockade of $D_{2}$ receptors at tubero-infundibular system ${ }^{4}$

\section{WEIGHT GAIN}

clozapine, olanzapine $>^{1}$ asenapine, paliperidone, quetiapine, risperidone $>$

${ }^{1}$ amisulpride, aripiprazole, iloperidone, lurasidone, ziprasidone ${ }^{2}$

Blockade of $\mathrm{H}_{1}$ (and others including 5-HT ${ }_{2 C}$ and $M$ ) receptors ${ }^{5}$

\begin{tabular}{|c|}
\hline $\begin{array}{c}\text { SEDATION } \\
\text { clozapine }>^{1} \text { asenapine, olanzapine }>^{1} \text { quetiapine }>^{1} \text { other } \text { SGAPs }^{6} \\
\text { Blockade of brain } \text { H }_{1} \text { receptors }\end{array}$ \\
\hline $\begin{array}{c}\text { MEMORY IMPAIRMENT } \\
\begin{array}{c}\text { Associated with high blockade of brain muscarinic receptors in schizophrenia patients } \\
\text { Possible with clozapine }\end{array}\end{array}$ \\
\hline $\begin{array}{c}\downarrow^{\downarrow} \text { SEIZURE THRESHOLD } \\
\text { clozapine }>^{1} \text { olanzapine, quetiapine }>^{1} \text { other SGAPs }{ }^{9} \\
D_{\mathbf{2}}, \boldsymbol{H}_{\mathbf{1}} \text { and } \boldsymbol{\alpha}_{\mathbf{1}} \text { receptor blockade, actions at neurosteroids or by pharmacological kindling }{ }^{10}\end{array}$ \\
\hline PERIPHERAL (with/without brain component) \\
\hline $\begin{array}{c}\text { HYPERGLYCEMIA/HYPERLIPIDEMIA } \\
\text { Secondary to weight gain (see above) } \\
\text { Direct effects on glucose/lipid metabolism } \\
\text { clozapine, olanzapine, quetiapine }\end{array}$ \\
\hline $\begin{array}{c}\text { SEXUAL SIDE EFFECTS } \\
\text { clozapine, risperidone, olanzapine }>^{1} \text { aripiprazole, quetiapine, ziprasidone }{ }^{12} \\
\text { Hyperprolactinemia (see above) and blockade of peripheral } \boldsymbol{\alpha}, \mathbf{M} \text { and } \mathrm{H} \text { receptors }{ }^{13}\end{array}$ \\
\hline $\begin{array}{c}\text { ORTHOSTATIC HYPOTENSION } \\
\text { clozapine, iloperidone, risperidone, quetiapine, ziprasidone }{ }^{14} \\
\text { Blockade of peripheral } \alpha_{1} \text { receptors }\end{array}$ \\
\hline $\begin{array}{c}\text { ANTICHOLINERGIC SYMPTOMS } \\
\text { (Tachycardia, constipation, dry mouth, urinary retention, or blurred vision) } \\
{ }^{15} \text { clozapine }>^{1} \text { olanzapine }>^{1} \text { quetiapine } \\
\text { Blockade of peripheral muscarinic receptors }\end{array}$ \\
\hline $\begin{array}{c}\text { NAUSEA } \\
\text { aripiprazole, lurasidone, ziprasidone } \\
\text { Unknown }^{16}\end{array}$ \\
\hline 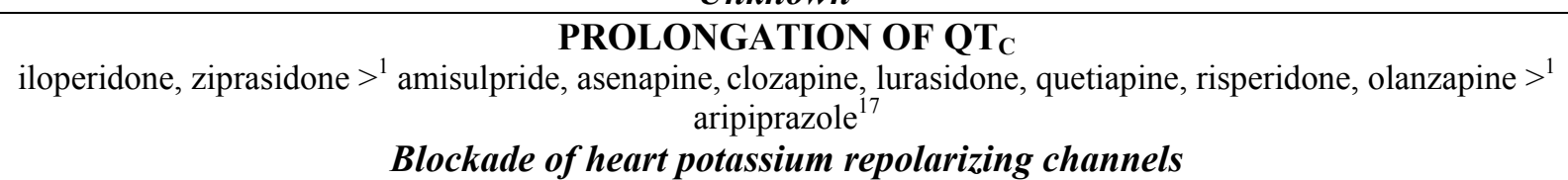 \\
\hline $\begin{array}{c}\text { AGRANULOCYTOSIS } \\
\text { clozapine }(<1 \%) \\
\text { Probably immunological } \\
\text { NEUTROPENIA (very rare) } \\
\text { Possibly ALL } \\
\text { Unknown }\end{array}$ \\
\hline $\begin{array}{c}\text { RISK FOR HEAT STROKE (very rare) } \\
\text { Most published cases also involve FGAPs }{ }^{18} \\
\text { Dopaminergic blockade interferes with temperature regulation } \\
\text { uscarinic blockade from antinarkinsonian or from AP (see anticholinergic) in }\end{array}$ \\
\hline
\end{tabular}

Figure 5. Pharmacodynamics of safety for second-generation antipsychotics 
5-HT: serotonin receptor; ADR: adverse drug reaction; AP: antipsychotic; D: dopamine receptor; FGAP: first-generation antipsychotic; $\mathrm{H}$ : histamine receptor; M: muscarinic receptor; SGAP: second-generation antipsychotic.

${ }^{1}$ Drugs preceding ">" will produce this ADR more frequently than drugs following ">".

${ }^{2}$ Data from a comprehensive review [43] supplemented with data on asenapine [44], iloperidone [45] and lurasidone [46].

${ }^{3}$ Data from a comprehensive review [43] supplemented with data on asenapine [44], iloperidone [47] and lurasidone [46].

${ }^{4}$ All APs are $\mathrm{D}_{2}$ antagonists except for aripiprazole, a partial agonist. The lower propensity of SGAPs other than aripiprazole to cause extrapyramidal symptoms is explained by two theories: i) a high ratio between $5-\mathrm{HT}_{2 \mathrm{~A}} / \mathrm{D}_{2}$ receptors, and ii) low affinity and fast dissociation from $\mathrm{D}_{2}$ (only clozapine and quetiapine will be "atypical" since they are displaced by endogenous dopamine) [48].

${ }^{5}$ Studies relating weight gain within different APs and receptor affinity indicate that $\mathrm{H}_{1}$ affinity is the best predictor of weight gain. Some animal studies indicate that $\mathrm{H}_{1}$ blockade of other receptors (particularly 5$\mathrm{HT}_{2 \mathrm{C}}$ and muscarinic) may be needed to produce hyperphagia in animal studies [48].

${ }^{6}$ Data from a comprehensive review [49] supplemented with data on asenapine [44] and iloperidone [45]. ${ }^{7} \mathrm{H}_{1}$ antagonism is probably the major contributing mechanism to sedation but other receptor blockade may also contribute. Aripiprazole and ziprasidone have also been associated with early insomnia and activation [50]. It is unknown whether these compounds' pharmacodynamic differences or individual susceptibility explain this activation.

${ }^{8}$ Blockade of $\mathrm{M}_{1}$ and $\mathrm{M}_{2}$ receptors has been associated with impaired learning and memory in animal studies [51]. It is difficult to detect cognitive impairment in the context of schizophrenia but high antimuscarinic activity was associated with worse memory functioning in an AP meta-analysis. Clozapine had a worse profile than risperidone and olanzapine [52]. Clozapine has definitively high antimuscarinic activity. Olanzapine and high doses of quetiapine may also be associated with clinically relevant antimuscarinic activity [52]. Thus, olanzapine and high doses of quetiapine may occasionally be associated with memory impairment.

${ }^{9} \mathrm{~A}$ comprehensive review [53] provided no comparative data on amisulpride, asenapine, iloperidone, or lurasidone.

${ }^{10}[54]$.

${ }^{11}$ Other SGAPs may not have direct effects on glucose or lipid metabolism, but this has not been completely established.

${ }^{12} \mathrm{~A}$ meta-analysis provided no comparative data on amisulrpide, asenapine, iloperidone, or lurasidone [55].

${ }^{13}[55]$. Priapism is rare but is the most severe sexual ADR and is probably explained by $\alpha_{1}$ (and possible $\alpha_{2}$ ) receptor blockade [48].

${ }^{14}$ Clozapine, iloperidone, risperidone, quetiapine, and ziprasidone need dose titration to avoid orthostatic hypotension. Orthostatic changes are not seen after intramuscular injections of ziprasidone, so ziprasidone probably has low risk of orthostatic hypotension. Other SGAPs with lower risk for orthostatic hypotension are olanzapine (particularly in intramuscular preparation) and asenapine.

${ }^{15}$ Clozapine causes hypersalivation. It is believed that clozapine may be a partial agonist at $\mathrm{M}_{1}$ and $\mathrm{M}_{3}$ receptors. Norclozapine, clozapine's main metabolite, is definitively an allosteric agonist of $\mathrm{M}_{1}$ [51].

${ }^{16}$ Antipsychotics, because of their dopaminergic blockade, are considered anti-emetic drugs, so it is not known what mechanism explains the association of these three drugs with nausea in the first one or two weeks of treatment. Other SGAPs may also occasionally be associated with nausea.

${ }^{17}$ Data from a comprehensive review [43] supplemented with data on amisulpride [56], asenapine [44], iloperidone [57] and lurasidone [58].

${ }^{18}$ Most published cases including SGAPs also had FGAPs co-prescribed [59]. 
Table 1. Pharmacokinetic parameters of antiepileptics.

\begin{tabular}{|c|c|c|c|c|c|c|c|}
\hline & $\begin{array}{c}\text { Bioavail } \\
\text {-ability } \\
\text { (\%) }\end{array}$ & $\begin{array}{c}\text { Protein } \\
\text { binding } \\
\text { (\%) }\end{array}$ & $\begin{array}{l}\text { Half- } \\
\text { life (h) }\end{array}$ & $\begin{array}{l}\text { Most } \\
\text { important } \\
\text { way of } \\
\text { elimination }\end{array}$ & Other ways of elimination & Active metabolites & Non-linear kinetics \\
\hline \multicolumn{8}{|c|}{ FIRST GENERATION } \\
\hline Carbamazepine & $75-85$ & 75 & $5-26$ & $\mathrm{CYP}_{\mathrm{A}} 4^{2}$ & CYP2C8, CYP1A2, UGT2B7 & $\begin{array}{l}\text { Carbamazepine } \\
\text { epoxide }^{7}\end{array}$ & $\begin{array}{l}\text { Non-linear until } \\
\text { induction is stable }\end{array}$ \\
\hline Ethosuximide & $90-100$ & $<10$ & $25-70$ & CYP3A4 $^{2}$ & CYP2E1, renal & & \\
\hline Phenytoin & 90 & 90 & $7-80$ & CYP2C9 ${ }^{2}$ & $\begin{array}{l}\text { CYP2C19 (less important: } \\
\text { CYP2C18, CYP3A4) }\end{array}$ & & Non-linear ${ }^{6}$ \\
\hline Phenobarbital & $>95$ & $45-60$ & $70-130$ & $\mathrm{CYP}_{2 \mathrm{C}} 9^{2}$ & $\begin{array}{l}\text { CYP2C19, CYP2E1, } \\
\text { N-glucosidation, renal }\end{array}$ & & $\begin{array}{l}\text { Non-linear until } \\
\text { induction is stable }\end{array}$ \\
\hline Primidone & $>90$ & 10 & $5-20$ & CYP2C9 ${ }^{2}$ & $\begin{array}{l}\text { Renal, CYP2C19, CYP2E1, } \\
\text { N-glucosidation, }\end{array}$ & Phenobarbital & $\begin{array}{l}\text { Non-linear until } \\
\text { induction is stable }\end{array}$ \\
\hline Valproate & $>90$ & $70-95$ & $8-16$ & $\begin{array}{l}\text { Several } \\
\text { UGTs }\end{array}$ & $\begin{array}{l}\beta \text {-oxidation, CYP } 2 \text { C9 (other } \\
\text { CYPs are minor) }\end{array}$ & & $\begin{array}{l}\text { Non-linear for total } \\
\text { concentration }\end{array}$ \\
\hline \multicolumn{8}{|c|}{ SECOND GENERATION } \\
\hline Eslicarbazepine & $\sim 100$ & 30 & $13-20$ & $\mathrm{UGTs}^{3}$ & Renal & S-licarbazepine & \\
\hline Felbamate & 90 & $20-25$ & $11-25$ & CYP3A4 ${ }^{2}$ & Renal, CYP2E1, UGTs & & \\
\hline Gabapentin & $<65$ & 0 & $5-9$ & Renal & & & Non-linear ${ }^{6}$ \\
\hline Lacosamide & $\sim 100$ & $<15$ & $12-16$ & CYP2C19 ${ }^{2}$ & Renal & & \\
\hline Lamotrigine & $>95$ & 55 & 25 & $\mathrm{UGT}_{1 \mathrm{~A}} 4^{2}$ & & & \\
\hline Levetiracetam & 100 & $<10$ & $6-8$ & Renal & Esterase hydrolysis in blood & & \\
\hline Oxcarbazepine & $\sim 100$ & 40 & $7-12$ & Renal & UGTs & $\begin{array}{l}\text { MHD (monohydroxy } \\
\text { derivate) }\end{array}$ & \\
\hline Pregabalin & $>90$ & 0 & $5-7$ & Renal & & & \\
\hline Retigabine & 60 & 80 & $8-10$ & Acetylation & UGTs & & \\
\hline Rufinamide & 85 & 30 & 8-12 & $\begin{array}{l}\text { Carboxyles- } \\
\text { terases }\end{array}$ & & & \\
\hline Stiripentol & $\geq 70$ & 99 & $4.5-13$ & & $\begin{array}{l}\text { CYP1A2, CYP2C19, CYP3A4, } \\
\text { UGTs }^{4}\end{array}$ & & \\
\hline Tiagabine & $\sim 100$ & 96 & $5-9$ & CYP3A4 $^{2}$ & & & \\
\hline Topiramate & $\sim 100$ & $13-17$ & $10-30$ & Renal & CYP & & \\
\hline Vigabatrin & $>50$ & 0 & $4-7$ & Renal & & & \\
\hline Zonisamide & $\sim 100$ & 50 & $50-70$ & CYP3A4 $^{2}$ & $\mathrm{~N}$-acetylation transferase, renal & & \\
\hline
\end{tabular}


CYP: cytochrome P450; UGT: uridine diphosphate glucuronosyl transferase

${ }^{1}$ This refers to normal metabolism. Lack of polymorphic enzymes, as well as major inhibition or induction, can change the major way of eliminating the drug from the body. In some CYPs (e.g., CYP2C19) some patients do not have active enzymes; they are called poor metabolizers (PMs). Others may have too much enzyme; they are called ultrarapid metabolizers (UMs). If a drug is metabolized by a CYP associated with PMs or UMs, these subjects metabolize the drug in a different way than average subjects. Adding a potent inhibitor that completely inhibits an enzyme causes a PM "phenocopy" as long the inhibitor effects are present; adding an inducer causes a UM phenocopy as long the inducer effects are present.

${ }^{2}$ Any substrate competes with others for the corresponding enzyme and inhibits it; the potency of the inhibition is influenced by substrate affinity and dose. In most clinical situations competitive inhibition is probably irrelevant. In unusual polypharmacy situations, adding a competitive inhibitor (such as AEDs, which are not normally considered inhibitors) in a patient taking a drug with a narrow therapeutic window may affect another drug's drug metabolism due to inhibitor accumulation past the tipping point.

${ }^{3}$ Eslicarbazepine is a pro-drug that is activated by hepatic esterases to S-licarbazepine. S-licarbazepine is eliminated by UGTs and by the kidney (unchanged). ${ }^{4}$ There are four metabolic pathways. No specific enzyme can be considered as the most important enzyme.

${ }^{5} \mathrm{MHD}$ is also called licarbazepine. Oxcarbazepine is a pro-drug and is activated by a cytosolic arylketone reductase that converts it to MHD, the active drug.

${ }^{6}$ Metabolic saturation explains phenytoin non-linear kinetics. Protein binding saturation explains valproate non-linear kinetics for total serum concentrations.

Absorption saturation explains gabapentin and rufinamide nonlinear kinetics.

${ }^{7}$ Carbamazepine epoxide is metabolized by an epoxide hydroxylase. 
Table 2. Pharmacokinetic parameters of second-generation antipsychotics.

\begin{tabular}{|c|c|c|c|c|c|c|}
\hline & $\begin{array}{c}\text { Bioavailability } \\
(\%)\end{array}$ & $\begin{array}{c}\text { Protein } \\
\text { binding }(\%)\end{array}$ & $\begin{array}{l}\text { Half-life } \\
\text { (h) }\end{array}$ & $\begin{array}{l}\text { Most important way of } \\
\text { elimination }^{1}\end{array}$ & Other ways of elimination & Active metabolites \\
\hline Amisulpride & $43-48$ & 17 & 12 & Renal & Biliary & \\
\hline Aripiprazole & 87 & 99 & $48-68$ & CYP2D6 $^{2}$ & CYP3A4 & Dehydro-aripiprazole \\
\hline Asenapine & $35^{3}$ & 95 & $1-2$ & UGT $1 \mathrm{~A} 4^{2}$ & CYP1A2, CYP2D6, CYP3A4 & \\
\hline Clozapine & $12-81$ & 95 & $6-33$ & $\mathrm{CYP}_{1 \mathrm{~A}} 2^{2}$ & CYP2C19, CYP3A4, CYP2D6 & Norclozapine $^{5}$ \\
\hline Iloperidone & 96 & 93 & $20-24$ & CYP2D6 $^{2}$ & CYP3A4, CYP1A2, CYP2E1 & P88, ${ }^{6}$ P95 \\
\hline Lurasidone & $9-19^{4}$ & 99 & 18 & CYP3A4 $^{2}$ & & ID-14823 \\
\hline Olanzapine & $60-80$ & 93 & $20-70$ & $\mathrm{CYP}_{1 \mathrm{~A} 2^{2}}$ & CYP2D6, UGT1A4, FMO & \\
\hline Paliperidone & 28 & 30 & 24 & Renal & UGT, CYP2D6, CYP3A4 & \\
\hline Quetiapine & NA & 83 & $5-8$ & CYP3A4 $^{2}$ & CYP2D6 & Norquetiapine \\
\hline Risperidone & 68 & 90 & $3-24$ & CYP2D6 $^{2}$ & CYP3A4, renal & 9-hydroxy-risperidone \\
\hline Ziprasidone & $60^{4}$ & 99 & $4-10$ & Aldehyde oxidase & CYP3A4 & \\
\hline
\end{tabular}

CYP: cytochrome P450; NA: not available; UGT: uridine diphosphate glucuronosyl transferase

${ }^{1}$ This refers to normal metabolism. Lack of polymorphic enzyme, as well as major inhibition or induction, can change the major way of eliminating the drug from the body. In some CYPs (e.g., CYP2D6 and CYP2C19) some patients do not have active enzymes, they are called poor metabolizers (PMs). Others may have too much enzyme; they are called ultrarapid metabolizers (UMs). If a drug is metabolized by a CYP associated with PMs or UMs, these subjects metabolize the drug in a different way than average subjects. Adding a potent inhibitor that completely inhibits an enzyme causes a PM "phenocopy" as long the inhibitor effects are present; adding an inducer causes a UM phenocopy as long the inducer effects are present. When patients are taking major inducers (carbamazepine, phenobarbital, phenytoin or primidone), CYP3A4 may became the most important enzyme eliminating aripiprazole or risperidone.

${ }^{2}$ Any substrate competes with others for the corresponding enzyme and inhibits it; the potency of the inhibition is influenced by substrate affinity and dose. In most clinical situations competitive inhibition is probably irrelevant. In unusual polypharmacy situations, adding a competitive inhibitor (such as SGAPs which are not normally considered inhibitors) in a patient taking a drug with a narrow therapeutic window may affect another drug's drug metabolism due to inhibitor accumulation past the tipping point.

${ }^{3}$ Asenapine is administered sublingually; drinking or eating $<10$ minutes after administration may decrease absorption.

${ }^{4}$ Decreased absorption when not administered with food.

${ }^{5}$ Norclozapine does not appear to have antipsychotic efficacy but it may contribute to anticholinergic effects and hypersalivation.

${ }^{6}$ It does not cross the blood-brain barrier. It may contribute to peripheral adverse drug reactions. 
Table 3. Effects of antiepileptic drugs on the most common drug-metabolizing enzyme systems.

\begin{tabular}{|c|c|c|c|c|}
\hline Antiepileptic & Induction & Enzymes & Inhibition & Enzymes \\
\hline \multicolumn{5}{|c|}{ First-Generation Antiepileptics } \\
\hline Carbamazepine & Yes & $\begin{array}{c}\text { CYP1A2, CYP2A6, } \\
\text { CYP2B6, CYP2C9, } \\
\text { CYP2C19, CYP3A4, } \\
\text { UGT1A1, UGT2B7, } \\
\text { UGT2B15, } \\
\text { Epoxide hydrolase }\end{array}$ & None $^{1}$ & N/A \\
\hline Ethosuximide & None $^{2}$ & $\mathrm{~N} / \mathrm{A}$ & None $^{1}$ & N/A \\
\hline $\begin{array}{l}\text { Phenobarbital, } \\
\text { Primidone }\end{array}$ & Yes & $\begin{array}{c}\text { CYP1A2, CYP2B6, } \\
\text { CYP2C8, CYP2C9, } \\
\text { CYP2C19, CYP2E1, } \\
\text { CYP3A4, UGT, Epoxide } \\
\text { hydrolase }\end{array}$ & None $^{1}$ & N/A \\
\hline Phenytoin & Yes & $\begin{array}{c}\text { CYP1A2, CYP2B6, } \\
\text { CYP2C8, CYP2C9, } \\
\text { CYP2C19, CYP3A4, } \\
\text { UGTs, Epoxide hydrolase }\end{array}$ & None $^{1}$ & N/A \\
\hline Valproic Acid & Unclear & & Yes & $\begin{array}{l}\text { CYP2C9, UGT1A4, } \\
\text { UGT2B7, Epoxide } \\
\text { hydrolase, N- } \\
\text { glucosidation }\end{array}$ \\
\hline \multicolumn{5}{|c|}{ Second-Generation Antiepileptics } \\
\hline Eslicarbazepine & Weak & CYP3A4 & Yes & CYP2C19 \\
\hline Felbamate & Weak & CYP3A4 & Yes & CYP2C19, $\beta$-oxidation \\
\hline Gabapentin & None $^{2}$ & N/A & None & N/A \\
\hline Lacosamide & None $^{2}$ & N/A & None $^{1}$ & N/A \\
\hline Lamotrigine & Weak & UGT & None $^{1}$ & $\mathrm{~N} / \mathrm{A}$ \\
\hline Levetiracetam & None $^{2}$ & N/A & None & N/A \\
\hline Oxcarbazepine & Weak & CYP3A4, UGTs & Weak & CYP2C19 \\
\hline Pregabalin & None $^{2}$ & $\mathrm{~N} / \mathrm{A}$ & None & $\mathrm{N} / \mathrm{A}$ \\
\hline Retigabine & None $^{2}$ & $\mathrm{~N} / \mathrm{A}$ & None & $\mathrm{N} / \mathrm{A}$ \\
\hline Rufinamide & Weak & CYP3A4, UGTs & Weak & CYP2E1 \\
\hline Stiripentol & None $^{2}$ & N/A & Yes & $\begin{array}{l}\text { CYP1A2, CYP2C19, } \\
\text { CYP2D6, CYP3A4 }\end{array}$ \\
\hline Tiagabine & None $^{2}$ & N/A & None $^{1}$ & $\mathrm{~N} / \mathrm{A}$ \\
\hline Topiramate & Weak & CYP3A4, $\beta$-oxidation & Weak & CYP2C19 \\
\hline Vigabatrin & None $^{2}$ & $\mathrm{~N} / \mathrm{A}$ & None & $\mathrm{N} / \mathrm{A}$ \\
\hline Zonisamide & None $^{2}$ & N/A & None $^{1}$ & N/A \\
\hline
\end{tabular}

CYP: cytochrome P450; N/A: not applicable; UGT: uridine diphosphate glucuronosyl transferase

${ }^{1}$ None means that the antiepileptic is not a clinically relevant inhibitor. Antiepileptic drugs, as any substrate (see Table 1), can behave as a competitive inhibitor and in rare circumstances this inhibition may have clinical relevance.

${ }^{2}$ None means that the antiepileptic is not a clinically relevant inducer. 
Table 4. Summary of pharmacokinetic drug interactions between antiepileptics and second-generation antipsychotics.

\begin{tabular}{|c|c|c|c|}
\hline Antiepileptic & Antipsychotic & Effect & Proposed mechanism \\
\hline \multirow[t]{7}{*}{ Carbamazepine } & Aripiprazole & Mean AUC decrease by $71 \%$ and 4 -fold increase in clearance & CYP3A4 induction \\
\hline & Clozapine & Decrease in plasma clozapine concentrations by $50 \%$ & $\begin{array}{l}\text { CYP1A2 and CYP3A4 } \\
\text { induction }\end{array}$ \\
\hline & Olanzapine & Decrease in olanzapine dose-normalized concentrations by $36-71 \%$ & CYP1A2 and UGT induction \\
\hline & Paliperidone & Decrease in steady-state $\mathrm{C}_{\max }$ and AUC of paliperidone by $37 \%$ & Renal P-gp induction \\
\hline & Quetiapine & $\begin{array}{l}\text { Decrease of quetiapine peak plasma concentration }\left(\mathrm{C}_{\max }\right) \text { by } 80 \% \text {, } \\
\text { AUC by } 87 \% \text { and a } 7.5 \text {-fold increase of its oral clearance }\end{array}$ & CYP3A4 induction \\
\hline & Risperidone & Decrease in risperidone total active moiety concentrations by $50 \%$ & CYP3A4 induction \\
\hline & Ziprasidone & Decrease in ziprasidone AUC by $36 \%$ & CYP3A4 induction \\
\hline \multirow[t]{4}{*}{ Lamotrigine } & Clozapine & No significant changes in plasma clozapine concentrations & \\
\hline & Olanzapine & Moderate elevation of plasma olanzapine concentrations by $15 \%$ & UGT1A4 competitive inhibition \\
\hline & Quetiapine & Moderate decrease of plasma quetiapine concentrations by $17 \%$ & \\
\hline & Risperidone & No significant changes in plasma risperidone concentrations & \\
\hline Oxcarbazepine & $\begin{array}{l}\text { Clozapine } \\
\text { Olanzapine } \\
\text { Risperidone }\end{array}$ & No significant changes in plasma concentrations of antipsychotics & \\
\hline Phenobarbital & Clozapine & Decrease in plasma clozapine concentrations by $35 \%$ & $\begin{array}{l}\text { CYP1A2, CYP3A4 and UGT } \\
\text { induction }\end{array}$ \\
\hline Phenytoin & Quetiapine & $\begin{array}{l}\text { Decrease by } 80 \% \text { of plasma quetiapine concentrations and } 5 \text {-fold } \\
\text { increase of its clearance }\end{array}$ & CYP3A4 induction \\
\hline Topiramate & $\begin{array}{l}\text { Clozapine } \\
\text { Olanzapine } \\
\text { Quetiapine } \\
\text { Risperidone }\end{array}$ & No significant changes in plasma concentrations of antipsychotics & \\
\hline \multirow[t]{5}{*}{ Valproic acid } & Aripiprazole & Decrease in plasma aripiprazole concentrations by $24 \%$ & $\begin{array}{l}\text { CYP3A4 and/or gastrointestinal } \\
\text { P-gp induction }\end{array}$ \\
\hline & Clozapine & $\begin{array}{l}\text { Variable results reported with plasma clozapine concentrations } \\
\text { slightly increased, slightly decreased or unchanged }\end{array}$ & \\
\hline & Olanzapine & Decrease in plasma olanzapine concentrations by $18-50 \%$ & CYPs and/or UGT induction \\
\hline & Quetiapine & No significant changes in plasma quetiapine concentrations & \\
\hline & Risperidone & No significant changes in plasma risperidone concentrations & \\
\hline
\end{tabular}

AUC: area under the curve; CYP: cytochrome P450; P-gp: P-glycoprotein; UGT: uridine diphosphate glucuronosyl transferase. 
Table 5. Practical summary of antiepileptic and second-generation antipsychotic drug interactions

\begin{tabular}{|c|c|c|c|}
\hline ANTIEPILEPTICS & SGAPs & OUTCOME & ACTIONS \\
\hline \multirow{6}{*}{$\begin{array}{l}\text { PK DI. Powerful inducers: } \\
\text { carbamazepine, phenobarbital } \\
\text { phenytoin, primidone }\end{array}$} & & \multirow{5}{*}{$\begin{array}{l}\text { A. } \downarrow \text { level 2-4 wks after adding inducer } \\
\uparrow \text { level 2-4 wks after D/C inducer }\end{array}$} & A. In absence of TDM use correction factor: \\
\hline & quetiapine, lurasidone? $>^{1}$ & & $5^{2}$ \\
\hline & \multirow{3}{*}{\begin{tabular}{|l|} 
olanzapine, clozapine $^{2}>^{1}$ \\
aripiprazole, iloperidone, $\mathrm{r}$ \\
asenapine? $>^{1}$ \\
\end{tabular}} & & $2-4$ \\
\hline & & & 2 \\
\hline & & & Unknown \\
\hline & amisulpride, paliperidone, ziprasidone & Not relevant & Possibly no clinically relevant changes \\
\hline $\begin{array}{l}\text { PK DI. Mild inducers: }{ }^{3} \\
\text { eslicarbazepine, felbamate, } \\
\text { oxcarbazepine, }{ }^{4} \text { topiramate, }{ }^{4} \\
\text { rufinamide }\end{array}$ & $\begin{array}{l}\text { quetiapine, lurasidone? }>^{1} \\
\text { olanzapine, clozapine }^{2}>^{1} \\
{\text { aripiprazole, iloperidone,risperidone }>^{1}}^{1} \\
\text { asenapine? }>^{1} \\
\end{array}$ & $\begin{array}{l}\downarrow \text { mild level 2-4 wks after adding inducer } \\
\uparrow \text { mild level 2-4 wks after D/C inducer }\end{array}$ & $\begin{array}{l}\text { A. Monitor for } \downarrow \text { efficacy after adding inducer } \\
\text { B. Monitor for ADRs after discontinuing inducer }\end{array}$ \\
\hline \multirow[t]{2}{*}{ PK DI. valproate } & olanzapine, & $\downarrow$ mild level & \multirow{2}{*}{$\begin{array}{l}\text { A. Be aware } \\
\text { Can't rule out occasional clinical relevance }\end{array}$} \\
\hline & clozapine $^{2}$ & mild $\downarrow$ or $\uparrow$ level & \\
\hline PD DI. valproate & SGAP & $\uparrow$ efficacy in mania/maintenance ${ }^{5}$ & $\begin{array}{l}\text { A. Be aware } \\
\text { B. Monitor for ADRs }\end{array}$ \\
\hline \multirow{3}{*}{$\begin{array}{l}\text { PD DI. } \\
\text { FGAEDs, topiramate }>^{1} \\
\text { Other }\end{array}$} & clozapine, asenapine,olanzepine > & \multirow[t]{3}{*}{ Additive sedation risk } & \multirow[t]{3}{*}{ A. Monitor for sedation } \\
\hline & quetiapine $>$ & & \\
\hline & Other & & \\
\hline $\begin{array}{l}\text { Absence of PD DI. } \\
\text { felbamate, lacosamide, } \\
\text { lamotrigine, tiagabine }\end{array}$ & aripiprazole, ziprasidone & $\begin{array}{l}\text { These AEDs and SGAPs may not be } \\
\text { sedating }\end{array}$ & Be aware \\
\hline \multirow{3}{*}{$\begin{array}{l}\text { PD DI. } \\
\text { carbamazepine, gabapentin } \\
\text { pregabalin, valproate }\end{array}$} & clozapine, olanzapine $>^{1}$ & \multirow[t]{3}{*}{ Additive weight gain risk } & \multirow{3}{*}{$\begin{array}{l}\text { A. Monitor weight } \\
\text { B. Monitor serum glucose and lipids }{ }^{6}\end{array}$} \\
\hline & $\begin{array}{l}\text { asenapine, paliperidone, quetiapine, } \\
\text { risperidone }>^{1}\end{array}$ & & \\
\hline & $\begin{array}{l}\text { amisulpride, aripiprazole, iloperidone, } \\
\text { lurasidone, ziprasidone }\end{array}$ & & \\
\hline $\begin{array}{l}\text { PD DI. } \\
\text { topiramate, zonisamide }^{7}\end{array}$ & SGAPs & Weight loss & Be aware \\
\hline PD DI. AEDs & SGAPs & Additive impaired swallowing risk $^{8}$ & $\begin{array}{l}\text { Monitor closely in patients with intellectual } \\
\text { disability or dementia }\end{array}$ \\
\hline $\begin{array}{l}\text { PD DI. carbamazepine, } \\
\text { phenobarbital, phenytoin, } \\
\text { primidone }>^{1} \\
\text { oxacarbazepine, valproate }\end{array}$ & amisulpride, paliperidone, risperidone & Possible additive osteoporosis risk & Monitor closely \\
\hline PD DI. valproate rarely ${ }^{9}$ & SGAPs more rarely $^{10}$ & Possible additive pancreatitis risk & A. Be vigilant (can be lethal) \\
\hline $\begin{array}{l}\text { PD DI. } \\
\text { carbamazepine very rarely }\end{array}$ & clozapine rarely & Both have risk for agranulocytosis & DO NOT COMBINE \\
\hline PD DI. valproate rarely & SGAPs rarely & Both associated with leucopenia & A. Be vigilant (can be lethal) \\
\hline $\begin{array}{l}\text { PD DI. } \\
\text { topiramate, zonisamide rarely }\end{array}$ & $\begin{array}{l}\text { SGAPs rarely } \uparrow \text { risk with } \\
\text { anticholinergic drugs }{ }^{11}\end{array}$ & Both associated with heat stroke & $\begin{array}{l}\text { In elderly and/or exposed to strenuous exercise/ } \\
\text { high temperatures: } \\
\text { A. Be vigilant (can be lethal): }\end{array}$ \\
\hline
\end{tabular}


ADR: adverse drug reaction; AED: antiepileptic drug; FGAED: first-generation antiepileptic drug; PD DI: pharmacodynamic drug interaction; PK DI: pharmacokinetic drug interaction; SGAP: second-generation antipsychotic; SGAED: second-generation antiepileptic drug; ?: reflects that information on asenapine and lurasidone is limited. It is likely that asenapine may be influenced by potent inducers but it has not been studied.

${ }^{1}$ Drugs preceding ">" will produce a more powerful outcome than the drugs listed on the following line.

${ }^{2}$ Please be aware that a correction factor of 5 was suggested by a phenytoin pharmacokinetic study by Wong et al. [80], but a correction factor of 7.5 was suggested by a carbamazepine pharmacokinetic study [56]. Rifampin, a CYP3A4 inducer, increased lurasidone metabolism by a factor of 5 .

${ }^{3}$ The risk of SGAP-induction reflects what we know from powerful AED inducers.

${ }^{3}$ High doses of oxcarbazepine $(\geq 1500 \mathrm{mg} / \mathrm{d})$ or TMP $(\geq 200 \mathrm{mg} / \mathrm{d})$.

${ }^{5}$ The combination of valproate with SGAPs may be more effective than monotherapy. This is particularly well established in mania; this type of combination for bipolar maintenance is standard clinical practice. As far as we know, there is no such data for additive effects for the combination of carbamazepine with SGAPs but this combination is frequently recommended for maintenance by pharmacological guidelines. Any study trying to establish the additive effects of carbamazepine and SGAPs in bipolar disorder will need to correct for pharmacokinetic DIs. ${ }^{6}$ Serum glucose and lipid abnormalities may be associated with weight gain. Drugs can also produce direct effects on glucose and/or lipid metabolism. Clozapine, olanzapine and quetiapine have been definitively associated with hyperglycemia and hyperlipidemia independent of weight gain. Carbamazepine has been associated with increases in total cholesterol and high density lipoprotein (HDL) cholesterol. Some studies have associated phenytoin with hyperglycemia and increases in total cholesterol. Valproate has been associated with lower total cholesterol, which may be positive, but is also associated with lowering HDL and insulin resistance.

${ }^{7}$ Felbamate is associated with weight loss but it cannot be used for that indication due to its high risk for severe ADRs.

${ }^{8}$ Although it has not been studied: i) all SGAPs can interfere with swallowing and cause esophageal dysmotility, ii) AEDs can also interfere with swallowing, and iii) additive or synergistic pharmacodynamic DIs upon swallowing are likely.

${ }^{9}$ Valproate is definitively associated with pancreatitis but the mechanism is not known.

${ }^{10}$ Rarely, SGAPs have been associated with pancreatitis, but the connection is not completely established. Some of these cases of pancreatitis were associated with hypertriglyceridemia, which is a known risk factor for pancreatitis. Clozapine, olanzapine and quetiapine have been definitively associated with hyperlipidemias that can occur in the absence of obesity and are probably explained by the direct effects of the drugs on lipid metabolism.

${ }^{11}$ Clozapine, olanzapine and high doses of quetiapine have anticholinergic (antimuscarinic) activity. Antiparkinsonian drugs can be coprescribed with SGAPs and have high anticholinergic (antimuscarinic) activity. 